\title{
Revisiting traffic forecasting by port authorities in the context of port planning and development
}

\section{Francesco Parola ${ }^{1} \cdot$ Giovanni Satta ${ }^{1} \cdot$ Theo Notteboom $^{2,3,4,5} \cdot$ Luca Persico $^{1}$}

Accepted: 19 September 2020 / Published online: 9 October 2020

(c) Springer Nature Limited 2020

\begin{abstract}
This paper contributes to the extant debate on port planning and development by analysing current approaches and challenges for academics and port authorities with respect to traffic forecasting. First, we examine how academics approach traffic forecasting in ports based on an extensive literature review. Next, using a sample of 28 core ports in the European Union, we provide empirical evidence on traffic forecasting challenges for, and approaches by, port authorities. Our findings are discussed by focussing on five themes, i.e. formalized planning versus ad hoc investment decisions, the types and time horizons of port planning documents, forecasting methods and data sources, attitudes towards the disclosure of traffic forecasts and methods, and institutional issues affecting traffic forecasting exercises.
\end{abstract}

Keywords Forecasting $\cdot$ Strategic planning $\cdot$ Investment decisions $\cdot$ Port authority

\section{Introduction}

Seaports are economic assets and value-adding logistics nodes. Port planning and development face unprecedented managerial challenges, given the structural changes and trends in international trade and global supply chains, and the disruptive effects of economic shocks caused by financial, political, global health and environmental crises. The highly dynamic external environment in which ports operate demands

Theo Notteboom

theo.notteboom@gmail.com

1 Department of Business Studies and Italian Centre of Excellence in Logistics, Transport and Infrastructures, University of Genoa, Genoa, Italy

2 China Institute of FTZ Supply Chain, Shanghai Maritime University, 1550 Haigang Avenue, Pudong New Area, Shanghai 201306, China

3 Faculty of Business and Economics, University of Antwerp, Antwerp, Belgium

4 Maritime Institute, Ghent University, Ghent, Belgium

5 Antwerp Maritime Academy, Antwerp, Belgium 
an increased focus on resilience, agility and flexibility (Paixao and Marlow 2003; Vonck and Notteboom 2016; Notteboom and Haralambides 2020). This, in turn, imposes a growing attention from port managers on the analysis of future market trends and forecasting techniques. Port planning and development processes, in fact, require pro-active understanding of all tendencies and interrelationships in trade, maritime transport and logistics, as well as of the strategies and requirements of relevant port stakeholders (Parola and Maugeri 2013).

The above tendencies and relationships have affected cargo volumes handled in ports. Over the past two decades, academics and practitioners have paid attention to the study of traffic forecasting in ports. Traffic forecasting exercises can provide port authorities (PAs) and port-related stakeholders with useful and necessary information in view of port project-related decision-making and broader port strategy formulation (Talluri and Ryzin 2004; Notteboom et al. 2015).

Despite the advances made in forecasting techniques, the relevance and validity of traffic forecasts are under the scrutiny of port stakeholders, such as market players, government agencies and community groups. PAs are typically challenged to reassess the role and necessity of forecasting exercises in port planning and development processes; to choose and apply appropriate forecasting methods; to rightly interpret forecasting outputs; and to effectively communicate their traffic forecasts with stakeholders. In addition, port traffic forecasts should be able to support investment decisions, given the capital-intensive nature of the industry and the long payback periods of infrastructural investments. Hence, the forecasting exercise of a PA requires a solid knowledge of the port ecosystem and the key variables triggering change, as well as significant technical capabilities in terms of data gathering and data analysis, and a good dose of caution avoiding bias.

This paper examines current approaches and challenges for academics and port authorities, with respect to traffic forecasting in a port planning and development context. First, we examine how academics approach traffic forecasting in ports from a PA perspective. Based on extant academic literature, we will demonstrate that port traffic forecasting is a rather small academic research field in port economics and management, which has proposed and applied a range of qualitative, quantitative and hybrid methods to produce long-term traffic forecasts. Second, we provide empirical evidence on traffic forecasting challenges for, and approaches by, port authorities. After elaborating on the rationale behind traffic forecasting by port authorities and the complexity associated with forecasting, we analyse the approaches of port authorities to traffic forecasting using a sample of 28 core ports in the European Union. Our findings are discussed, focussing on five themes: (1) formalized planning versus ad hoc investment decisions, (2) the types and time horizons of port planning documents, (3) forecasting methods and data sources, (4) the attitude towards the disclosure of traffic forecasts and methods used, and (5) institutional issues affecting traffic forecasting exercises. The paper concludes with the main findings, research limitations and possible avenues for further research. 


\section{Academic approaches to traffic forecasting relevant to PAs}

Significant research efforts have been directed to forecasting cargo traffic and container throughput, as these constitute the relevant performance indexes on which future port planning and development should be grounded (Zhang et al. 2013; Lam et al. 2004). Extant port literature suggests that forecasts of cargo handling volumes provide PAs with useful inputs for basing their decisions and implementing strategies more effectively (Trujillo et al. 2002; Talluri and Ryzin 2004). Several scholars address the suitability and accuracy of various forecasting techniques, examining both qualitative and quantitative methods used to predict cargo traffic and container throughput (De Langen et al. 2012).

To investigate extant literature addressing viable forecasting techniques adopted by PAs in predicting cargo traffic and container throughput, we performed a systematic literature review along with a three-stage procedure, including: (a) planning, (b) execution, and (c) reporting (Tranfield et al. 2003). In the planning step (a) we defined the objective and set the perimeter of the review. For our aim, we focussed on academic papers from leading peer-review international journals, selected from the Scopus database. This was done by performing ad hoc queries with specific keywords, combining words related to "forecast", "port authority" as well as "cargo traffic" or "container throughput". In the second step (b) we followed the method proposed by Crossan and Apaydin (2010), which considers three phases: (i) definition of initial selection criteria, (ii) grouping publications by pertinence, (iii) analysis and synthesis.

Queries were carried out on papers published in the 2000-2018 period. This enabled us to identify an initial database, consisting of 57 papers potentially relevant for our purposes. The database was further screened to eliminate not pertinent manuscripts. In particular, the related abstracts have been read by the authors and two alternative labels were assigned by each coder to each manuscript (i.e. pertinent versus not pertinent). Abstracts receiving at least three "pertinent" labels were maintained in the database, whereas the others were eliminated, resulting in a rather modest shortlist of 42 papers focussed on forecasting techniques and predictive tools in port development. Note that PortEconomics.eu identified a total of 1353 academic papers on port economics and management published in the period 2000-2018, which makes the port traffic forecasting theme a small research area. The authors have read the 42 papers by replicating the aforementioned procedure: as a result, a final dataset of 22 relevant contributions emerged. Each sample manuscript was analysed and categorized by considering the object and aim of the analysis, the geographical scope, the methodology used and the time period. The results of this exercise are reported in Table 1.

The analysed papers propose qualitative, quantitative and mixed statistical methodologies for performing forecasts in the port domain. With respect to qualitative methods, Rashed et al. (2015) suggest scenario-based analysis as a viable tool for investigating the impact of economic and transport trends on future 


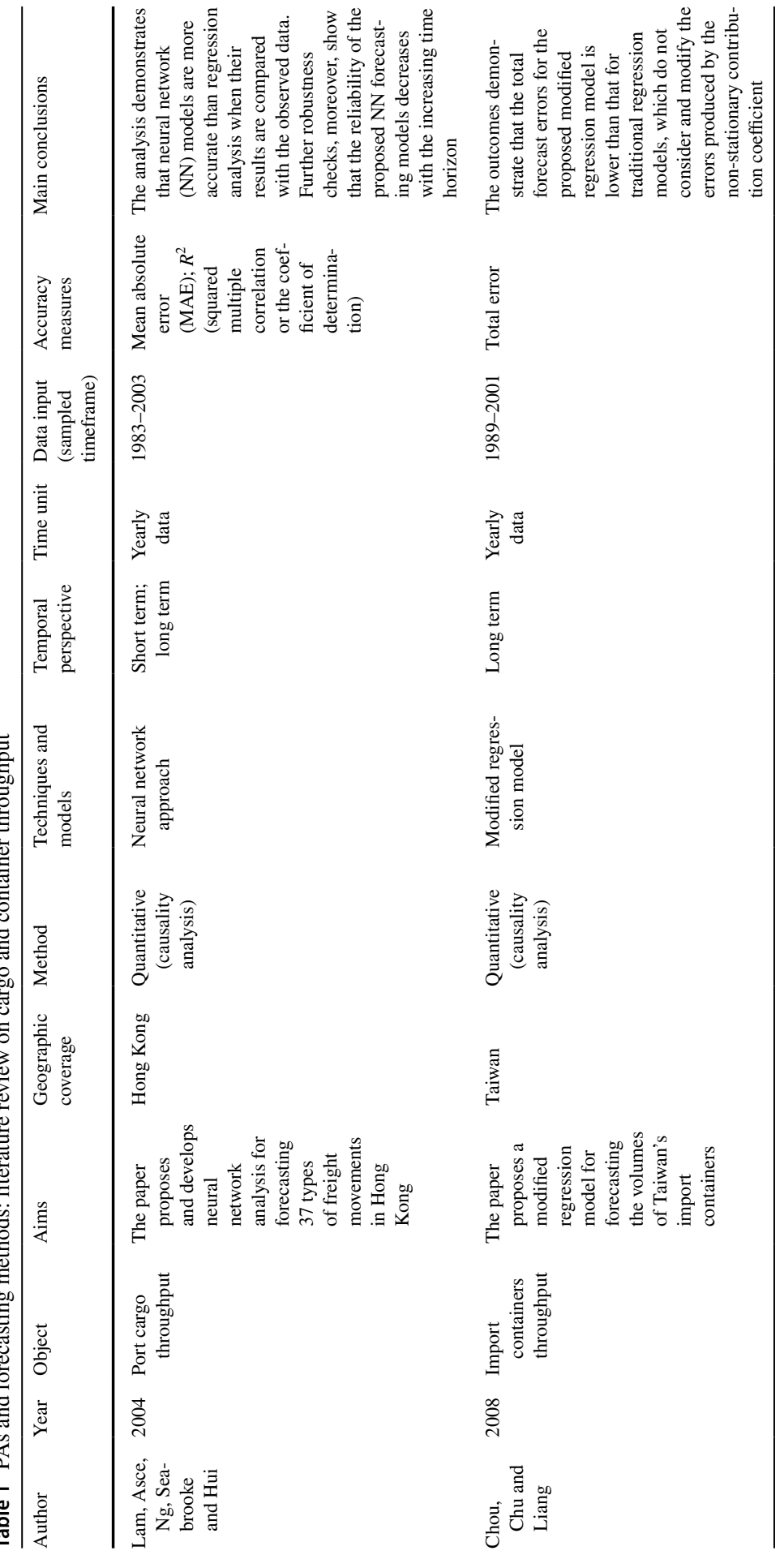




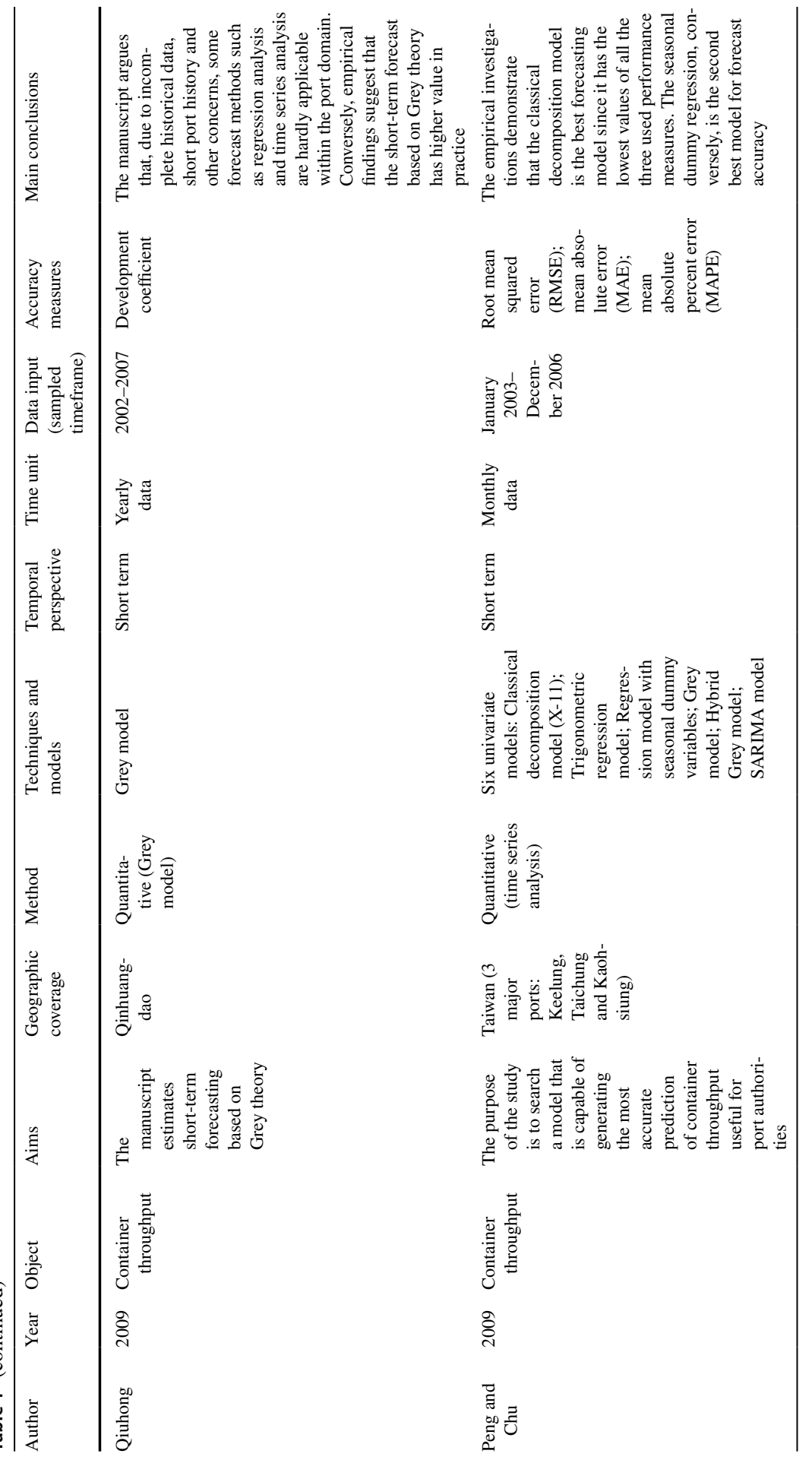

站 


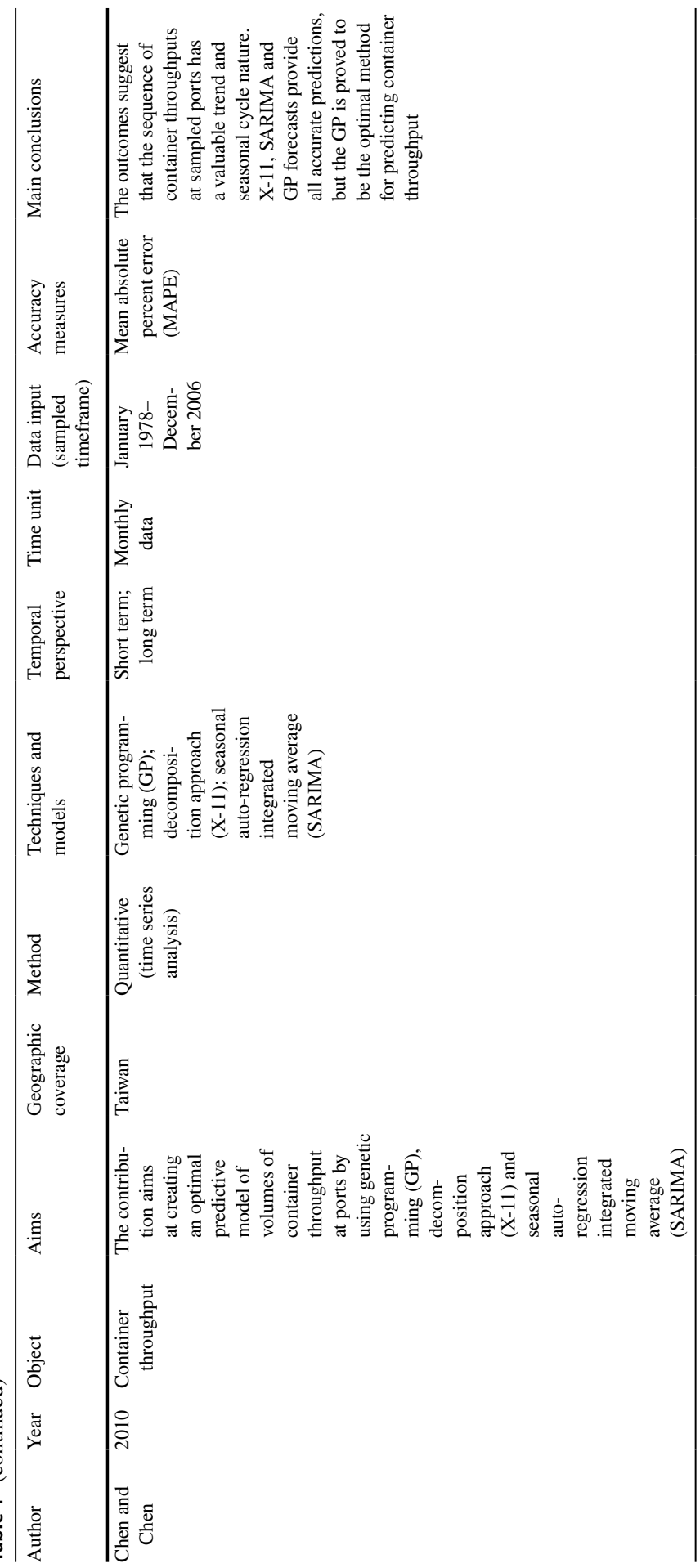




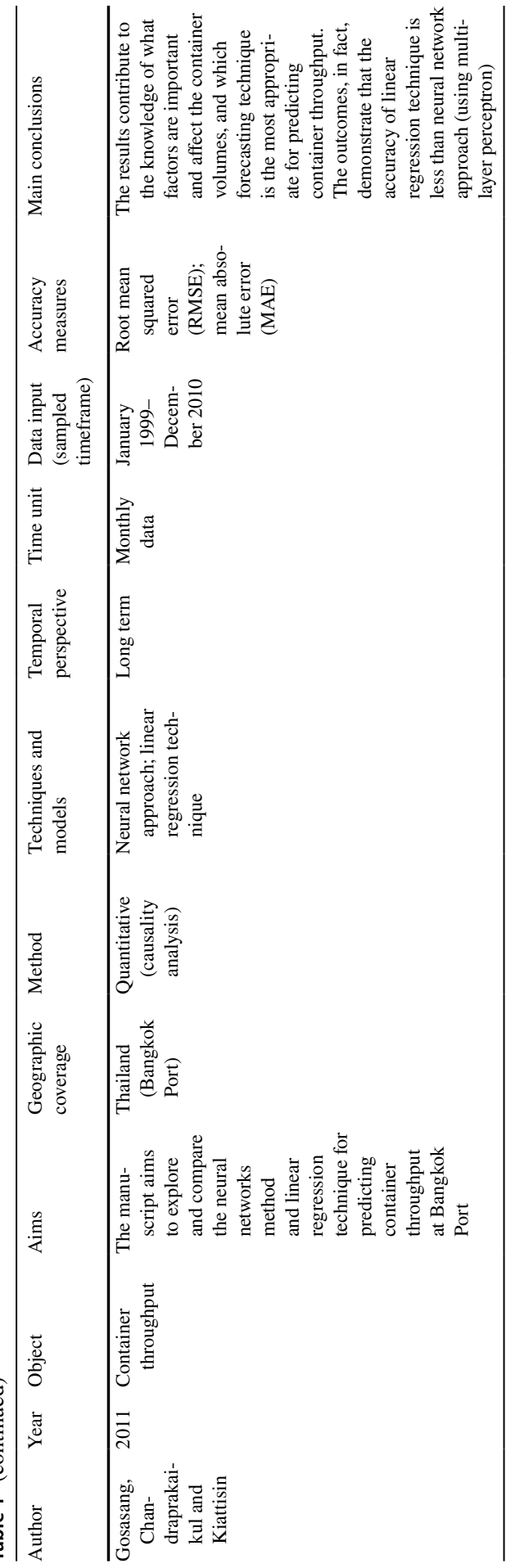

战。 


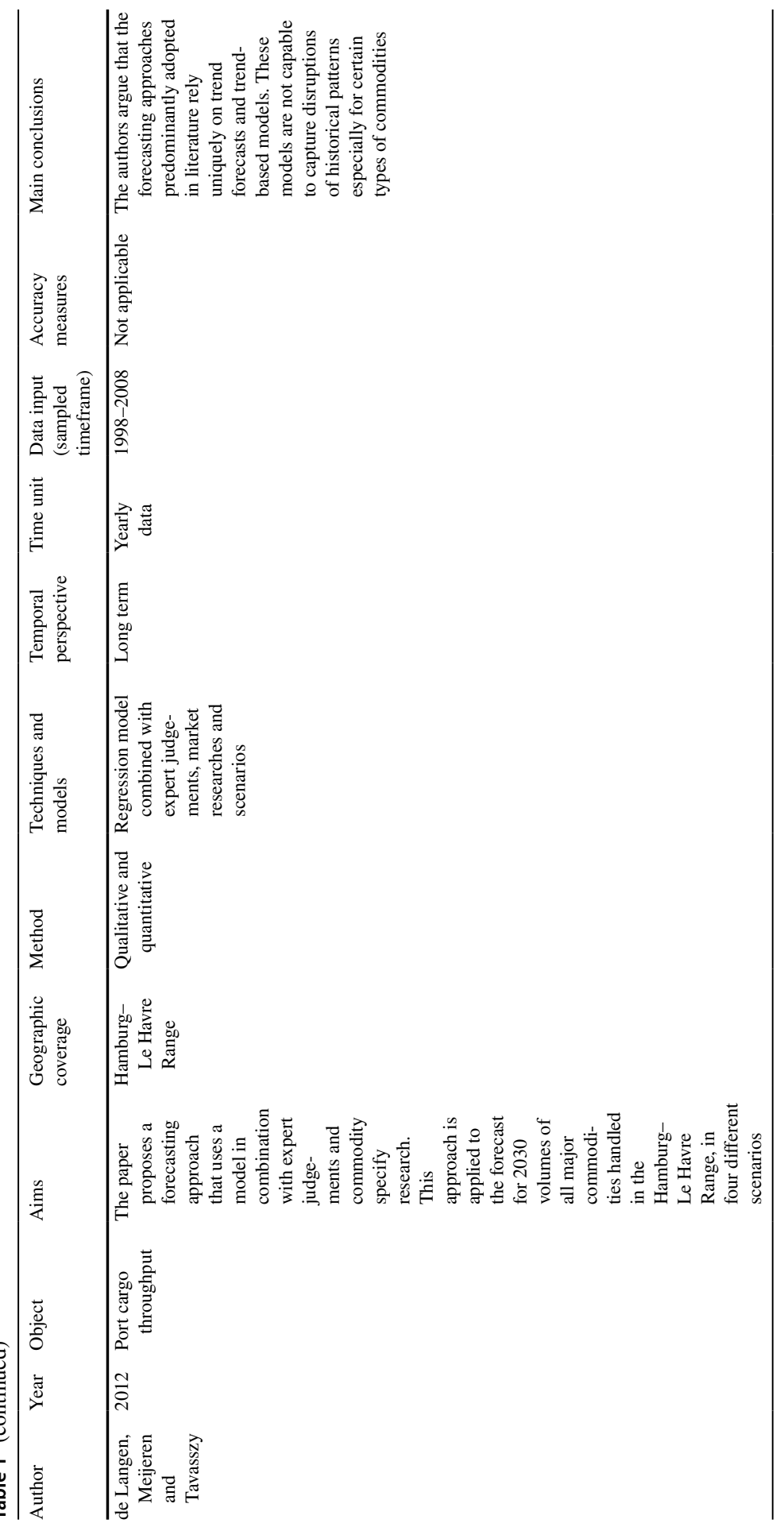




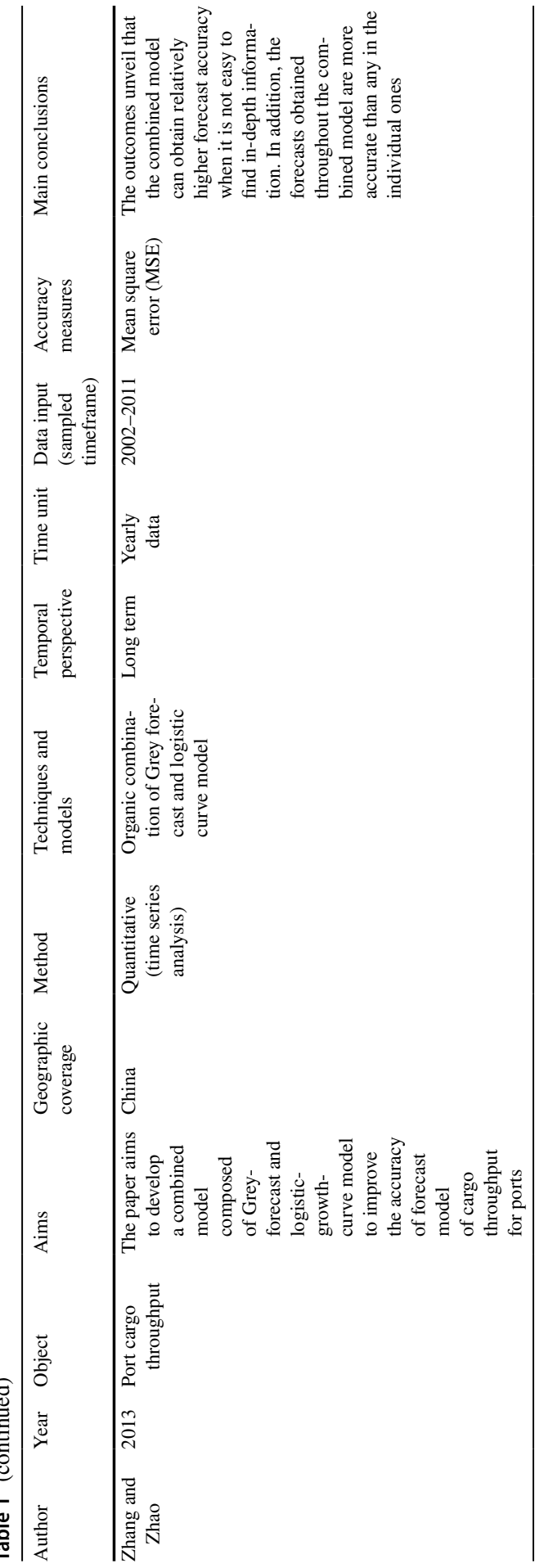

称。 


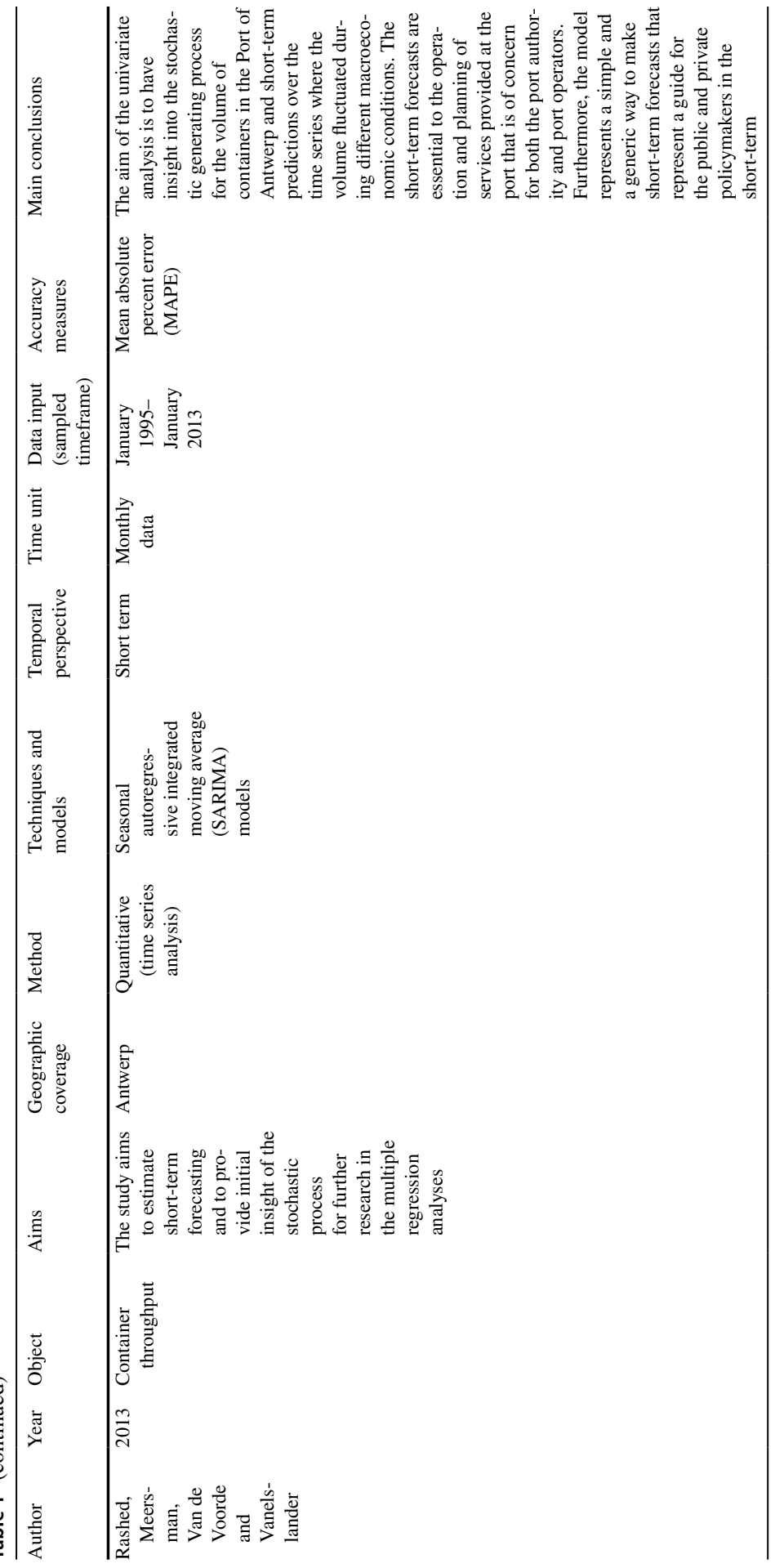




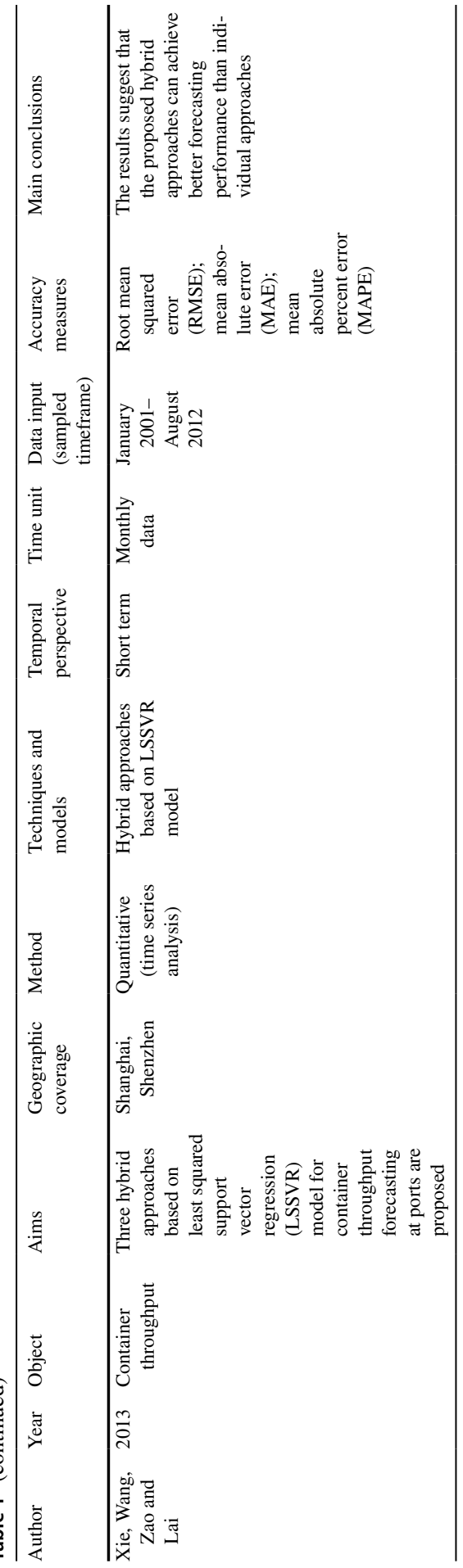

称。 


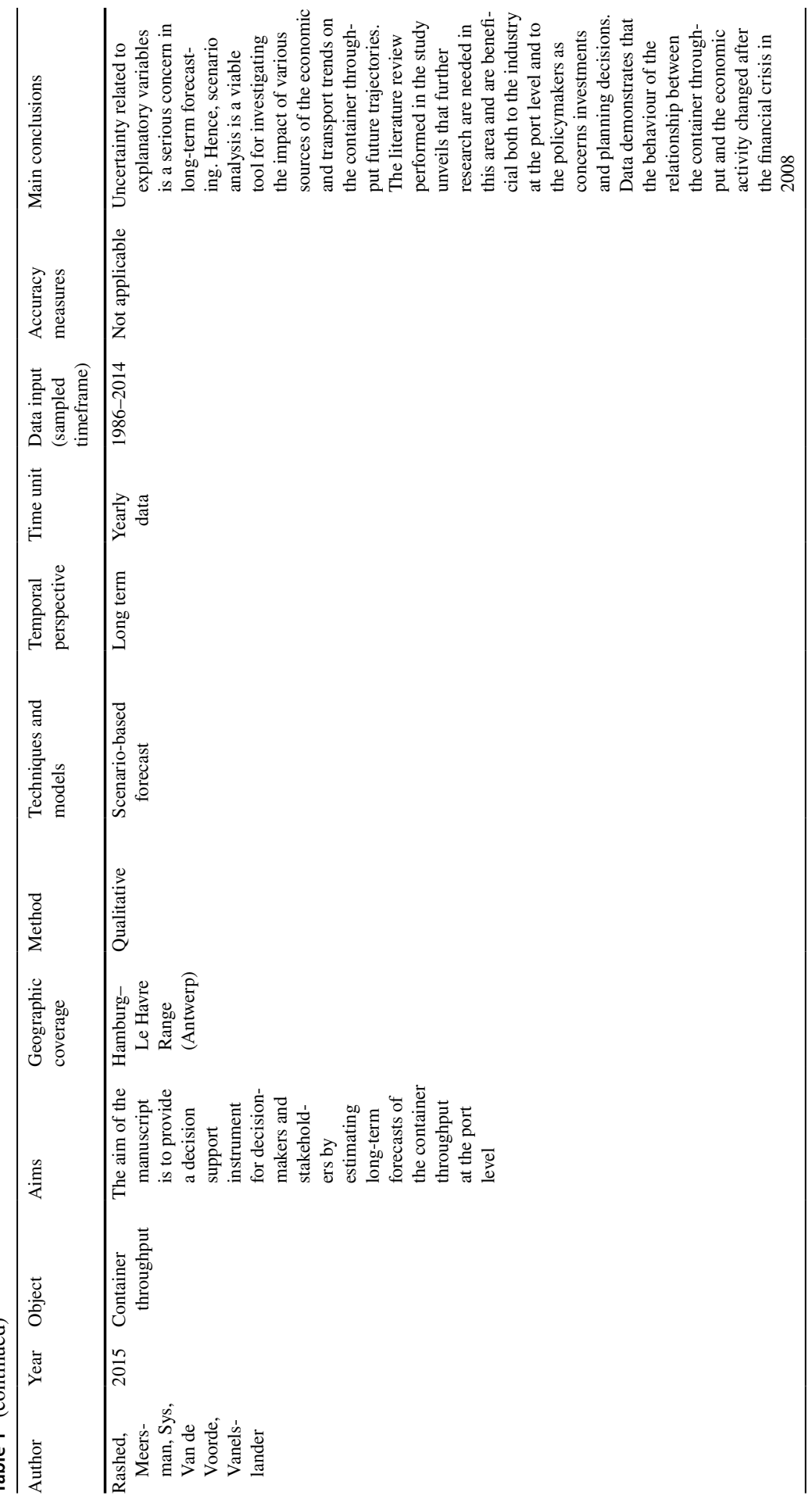




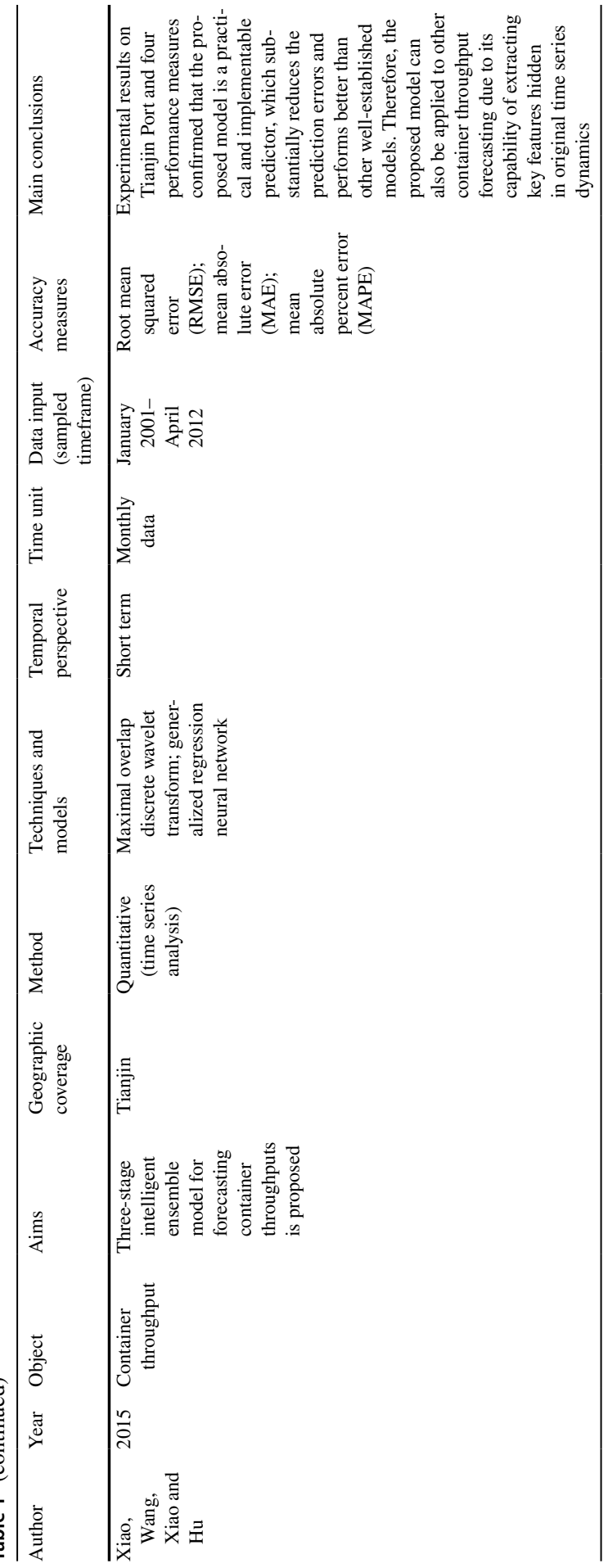

站。 


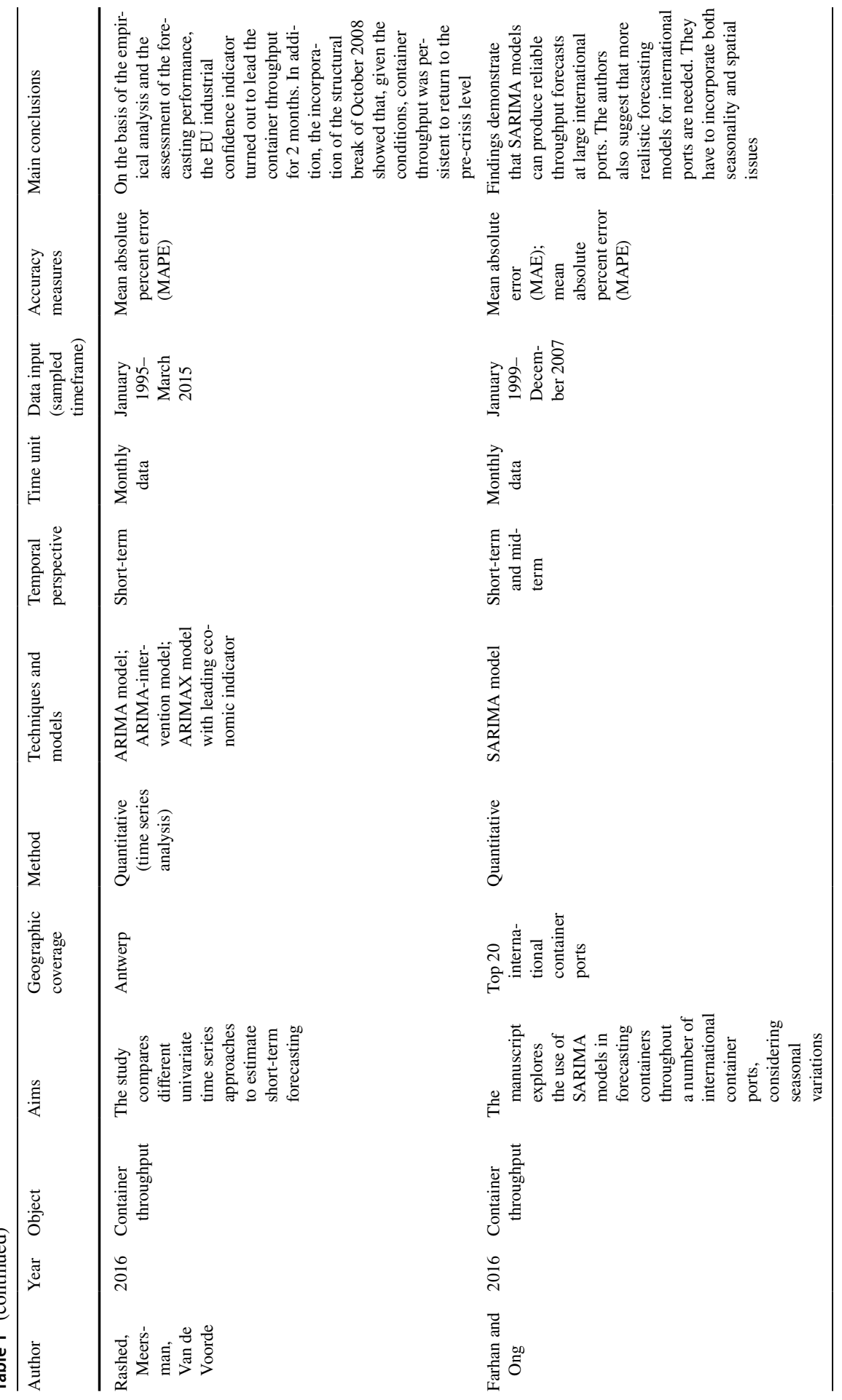




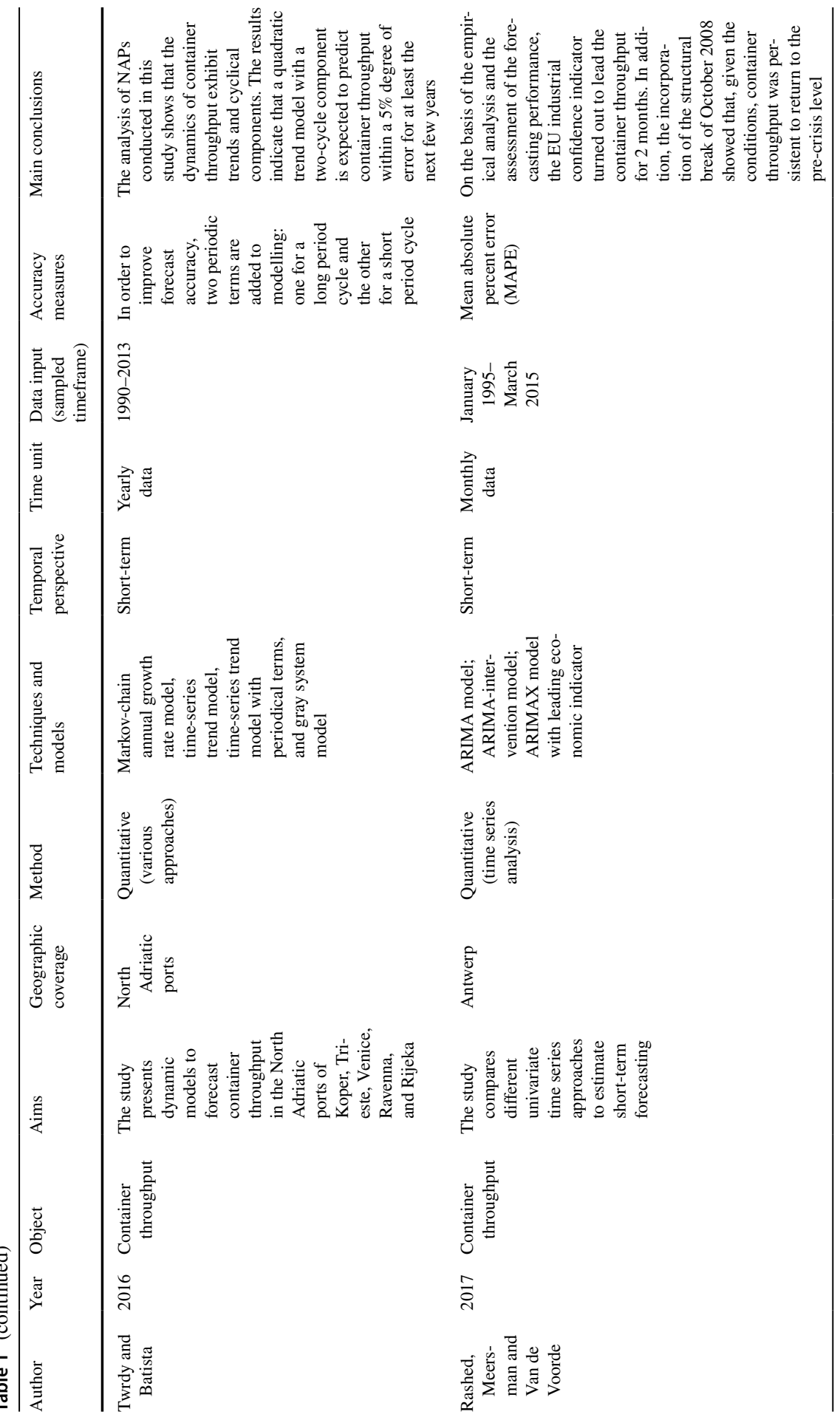

这。 


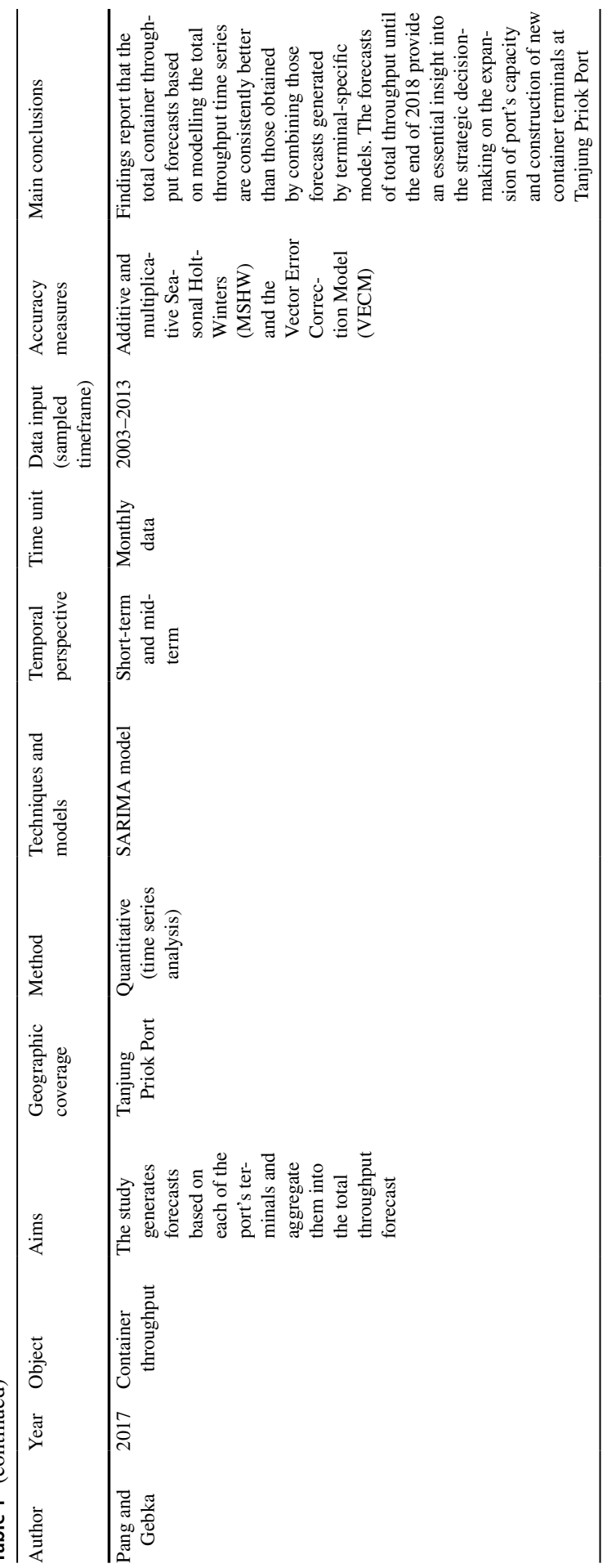




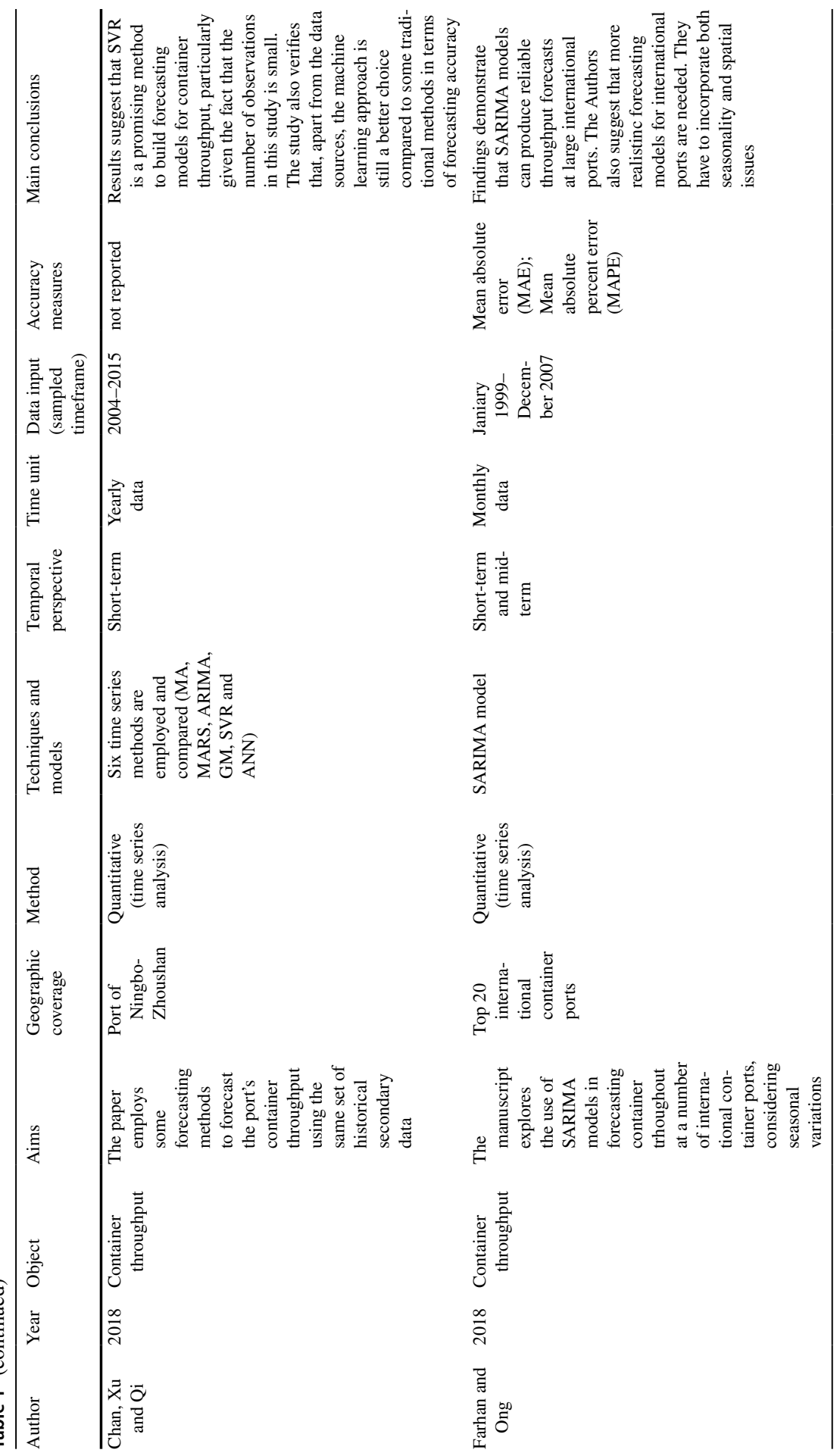

称。 


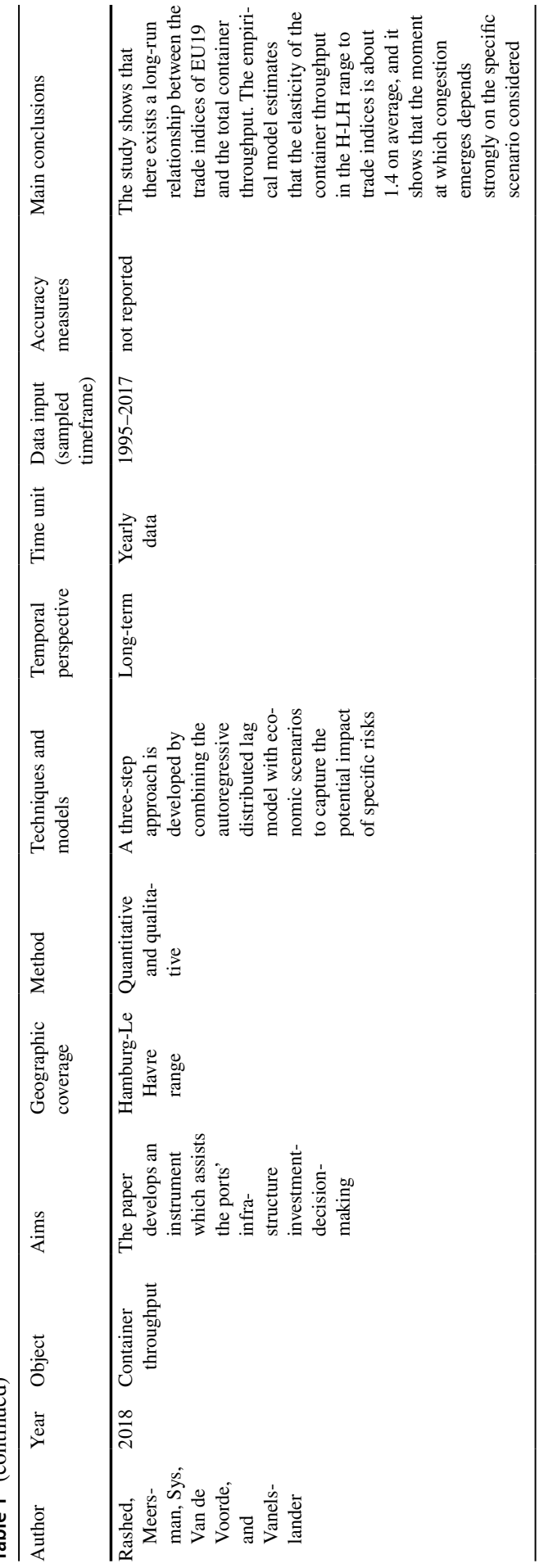

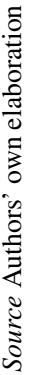


trajectories in container throughput. This approach provides PAs with a feasible range of values, which a specific (forecasted) variable could assume in the future.

Nonetheless, in some circumstances, qualitative forecasts do not provide port managers and decision-makers with exhaustive data and information for dealing with the challenges impacting port planning and development. In these cases, either quantitative or hybrid techniques are to be preferred. For example, Jiang and Lei (2009) focus on time series analysis and apply a nonlinear Grey model to forecast cargo throughput, whereas $\mathrm{Xu}$ (2011) proposes an autoregressive forecasting model to predict cargo throughput. Peng and Chu (2009) investigate which model generates the most accurate prediction of container throughput by testing six univariate models. In an empirical application on Taiwanese ports, the classical decomposition model emerges as the best forecasting model. The authors conclude that more sophisticated and complex statistical methods do not necessarily perform better than simpler ones. A lack of reliable data sources or inaccuracies in data gathering, for example, can lead to poor quality forecasts notwithstanding the sophistication of the forecasting methodology.

Several contributions focus on causal models. Lam et al. (2004) develop a neural network analysis to predict 37 types of freight movements in the Port of Hong Kong. Neural network models appear more accurate than regression analysis, especially in the short-term. Neural network analysis is demonstrated to be rather timeconsuming, requiring the gathering of heterogeneous data inputs, and, therefore, its application in the PA domain might present a number of difficulties.

Chou et al. (2008) propose a modified regression model to predict flows of Taiwan's import containers. Compared to traditional regression models, the modified model reduces the non-stationary predictive contribution coefficient produced by macro-economic variables.

Some academic contributions compare or combine various forecasting methods and techniques. Chen and Chen (2010) create an optimal predictive model for container throughput. For this purpose, they rely on genetic programming (GP), decomposition approach (X-11) and seasonal auto-regression integrated moving average (SARIMA). They find that the sequence of container throughputs at the sampled ports shows a clear trend and seasonal cycle both in the short and the longterm. X-11, SARIMA and GP forecasts provide accurate predictions, but GP is suggested as the optimal method for predicting container throughput.

Gosasang et al. (2011) compare the neural network method with a linear regression technique for predicting container throughput at the Port of Bangkok. The authors demonstrate that the accuracy of the linear regression technique is lower than the neural network approach, if a multilayer perspective is used.

Van Dorsser et al. (2012) propose a mix of quantitative and qualitative methods in their study on (very) long term forecasts of port throughput in the Le Havre-Hamburg range, including, in their framework system, dynamic modelling, judgement, and causal relations. They argue that port throughput forecasting literature supports the adoption of both trend extrapolation techniques and the use of causal relations. Their combined methodology is made up of three steps. First, they propose a probabilistic forecast of the working age population, paving on system dynamic modelling. Second, (expert) judgement is applied for defining 
(Bayesian) assumptions concerning the development of several variables (i.e. labour participation, annual working hours, and GDP output per hour) in order to derive the GDP forecast for the sample geographic area. Third, the authors calculate the port throughput forecast by scrutinizing the causal relation between GDP and port throughput.

Other scholars also rely on expert information and judgement to complement the outputs of the traffic forecasting models. Xiao et al. (2012) introduce an advanced hybrid forecasting methodology to extract the information hidden in the non-stationary and noise data (i.e. a novel feed forward neural network based on particle swarm optimization with adaptive genetic operator) and then adjust the forecast results of the model with knowledge from port experts. Empirical results on the Tianjin Port suggest that these forecasts are significantly more accurate than those generated by alternative techniques. De Langen et al. (2012) argue that extant PA forecasting approaches rely predominantly on trend-based predicting models, which cannot fully capture disruptions of historical patterns. This insight appears particularly relevant when considering the exposure of the port industry to economic or social shocks, as demonstrated by the COVID-19 pandemic. Consequently, their forecasting approach mixes econometric models with expert judgements and specific commodity insights to provide a solid empirical backbone for PA strategic decisions. However, these forecasting exercises lose significance if no specialized skills and competences are held by PA managers in this field. Moreover, De Langen et al. (2012) demonstrate that a disaggregated forecasting approach is needed at the level of commodity types, as each coherent commodity group has distinct throughput drivers and terminal requirements. For example, the authors considered three types of container flows (i.e. direct deepsea, shortsea and transhipment flows) using a different forecasting method for each one. Also Coto-Millán et al. (2005) conclude that inbound, outbound and sea-sea transhipment flows may require different model specifications, while Lam et al. (2004) argue that seaborne traffic and inland waterway traffic cannot be treated in the same way. All these studies, indeed, suggest the need for a commodity-wise approach in traffic forecasting.

Zhang et al. (2013) develop a model which combines Grey-forecast and logisticgrowth curve models aiming to improve the accuracy of cargo throughput forecasts. Through an empirical application to Chinese ports, they demonstrate that combined models can obtain a relatively higher forecast accuracy, whenever it is challenging to gather sufficient data through field or desk research, which is often the case for PA decision-makers.

Finally, Xie et al. (2013) propose three hybrid approaches based on a least squared support vector regression (LSSVR) model to forecast container throughput in two main Far East ports. Their outcomes demonstrate that the proposed hybrid approaches can achieve a better forecasting performance than individual approaches.

Although prior studies have provided useful insights on traffic forecasting by PAs in the context of port planning and development, a number of practical issues are rather under-explored. First, no prior studies have investigated the extent to which PAs effectively perform forecasting analyses to support their port planning and development exercises, which methodologies they rely on, as well as which output and information they disclose on this matter to stakeholders. By investigating 
empirical evidence from the industry, useful best practices and guidelines can be identified and disseminated among various actors. Second, extant literature has not yet focussed on the main concerns of port managers when engaging in forecasting activities. In this vein, a more structured investigation of these issues should support the development of a more conscious research agenda for improving scientific knowledge in this field.

For this purpose, in the next sections, we provide evidence on the most diffused forecasting practices among PAs, grounding on data and information released by 28 EU Core Ports. We investigate the challenges facing PAs when performing traffic forecasting as part of port planning and development activity.

\section{Approaches of port authorities to traffic forecasting}

\subsection{The rationale behind traffic forecasting by port authorities}

Investment decisions and capacity management in ports often require long-term forecasts (Peng and Chu 2009), particularly considering the long lifecycle of capital-intensive port infrastructure and the associated long-term horizon needed in the planning and development of new infrastructures or the upgrading/upsizing of existing facilities (Koppenjan 2005). As the design and construction of port infrastructure may take up to 5 years or more, and the infrastructure might be around for the next 50-100 years, public decision-makers and PAs are asked to present longterm traffic forecasts. The capital-intensive nature of the port business, combined with the timing imposed by infrastructure planning and implementation, lead to long payback periods for port investments (Satta 2017). The timing of a port capacity increase and a good assessment of future demands are crucial to position the port for sustained growth. Errors in demand forecasts and future (discounted) free cash flow estimations can mislead port managers and policymakers, causing both public and private economic and financial losses. Errors and biases in traffic-related projections can lead to improper decisions on port investments, which could, for instance, jeopardise the efficiency of privatization processes in developing countries, or the renegotiation and renewal of port concessions in developed economies (Trujillo et al. 2002).

A number of ongoing trends in ports further underline the need for reliable forecasting models capable of predicting various port-related variables and supporting public/private actors' decisions on planning of terminal facilities. New drivers include, among others, the increase in intra- and inter-port competition and the increasing magnitude of port investments (Parola et al. 2013b; Satta and Persico 2015). As competition and financial needs for port development increase, PAs, investors and other stakeholders need to rely on traffic demand forecasts more than ever to optimize/rationalize investment decisions.

Port authorities are typically the public actors guiding port planning and development. Despite this leading role awarded by law, PAs do not act alone or independently in shaping their planning framework and long-term investments but are subjected to an active stakeholder involvement. For performing traffic 
forecasts, PAs quite often need data input provided by other parties such as current concessionaires or bidders in new terminal concession procedures. Political, societal, financial and external competition factors ${ }^{1}$ and stakeholders can have an influence on port planning and investment decisions as well as underlying forecasts.

While PAs typically have to present long-term traffic forecasts in view of their need to justify port (infrastructure) investments, they might lack the capabilities, knowhow and/or resources to assess or assume the associated risks and uncertainties. When port land is concessioned by a landlord port authority to a terminal operator on a long-term basis, the risks and uncertainties linked to traffic forecasting are to some extent transferred to the concessionaire. Global terminal operators invest all over the world and are in a good position not only to forecast global economic trends but also to diversify their risk by spreading it out among terminals in different geographical regions.

Concessionaires hold most of the commercial and operational responsibilities and, for this reason, they have to define and implement business plans and investment programs over the entire concession duration. The contents of individual private plans are negotiated between the PA and the concessionaire not only during the awarding stage but also throughout the monitoring activity undertaken by the public authority on private firms. As private concessionaires look for profits and want to safeguard shareholders' interests, they need forecasting exercises for evaluating the future demand development, and for justifying their own future investment and organizational settings. The expected traffic volumes, coupled with planned employment levels and investment programs, are declared by the concessionaire in its business plans and then progressively validated by the PA over time. Therefore, the strategic planning realized by individual concessionaires constitutes an initial empirical and decisional base, enabling the PA to conceive its planning and forecasting activity.

The PA is called upon to stimulate and guide private concessionaires in their own business planning, also trying to harmonize such investment programs in terms of timing, sizing and technological levels. In so doing, the PA has to moderate the risk of overcapacity and potential conflicts arising from the co-location of activities. More importantly, the PA has to define the long-term direction of port development defining, among others, the future port size (land and water areas), the portfolio of commodities to be served and the related destination use of various facilities. Next to this, the forecasting analysis, on which an overarching and balanced PA planning should be grounded, is expected to be coherent, with the aggregate traffic/ capacity estimates contained in the business plans of concessionaires. Then, the PA

\footnotetext{
1 These factors include: political goals and pressure at various institutional layers, the evolution of cargo and passenger demand (including locked-in industrial activities), the availability of financial resources from public (e.g. transfer from the government, national and EU funding schemes etc.) and private (e.g. financial investors, concessionaires etc.) entities, societal acceptance (e.g. negative externalities etc.), territorial constraints (e.g. lack of space for expansion, risks deriving from the vicinity of port versus city activities etc.), inland logistics connectivity (e.g. number \& frequency of rail services, additional inland infrastructures, dry ports and logistics centres etc.), and actions by competing ports (e.g. early mover advantage, imitative behaviours, overcapacity concerns etc.).
} 
has to plan its own investments in line with demand expectations and forecasting, but also complementary to the investments planned by individual private actors in their business plans. This means that PA planning and forecasting have to create the infrastructural preconditions for enabling private concessionaires to realize their own projects and be commercially competitive.

Privatization and reform processes experienced by the port sector worldwide can change the role and process-related aspects of traffic forecasts. Port privatization results in an actor-based fragmentation of decision processes in the sector (Trujillo et al. 2002). The widespread diffusion of public-private partnerships in port infrastructure development and financing ( $\mathrm{Mu}$ et al. 2011; Panayides et al. 2015) adds further complexity to the decision processes in the port domain. PPP agreements allow public authorities to overcome budgetary constraints (Flinders 2005; Hammami et al. 2006), to compensate for their lack of expertise in operations, and to attract foreign direct investment (FDI). However, they also require the active participation of diverse players and actors in various phases of the overall terminal awarding process, including negotiations with public parties and other private bidders if a partnership is involved (Pallis et al. 2010; de Langen et al. 2012; Parola et al. 2013b). In addition, when PPP port projects are evaluated by private and public actors, different evaluation criteria and methodologies are applied, making forecasts even more difficult. Information asymmetries may also emerge during the implementation process (Trujillo et al. 2002).

Finally, the introduction of new public management (NPM) practices in the port industry has increased the role of managerial and technical tools in supporting the decisions of port managers and policy makers (Parola et al. 2013a). NPM aims to favour the adoption across public services of a market-oriented vision, the definition of strategy and planning, portfolio resources management and performance incentives, which can be typically found in private companies (Metcalfe and Richards 1990).

Thus, forecasts have become fundamental for port planning and development, as well as for supporting associated investment decisions, for managing processes in public-private partnerships, and for renewing concessions or land leases (Pallis et al. 2010; Parola et al. 2013b). In a volatile and highly competitive environment, port managers often need to resort to time-consuming and difficult business intelligence exercises and complex statistical tools (Tian et al. 2013).

\subsection{The complexity behind traffic forecasting}

Traffic forecasts are highly complex exercises, as they should capture uncertainties and the interdependencies between factors that can influence future traffic flows. When engaging in traffic forecasting, PAs or the experts engaged by the PAs, often assume that, in predicting future values, uncertainties can be addressed by sensitivity analyses or by considering different plausible scenarios. Therefore, as with all forecasting efforts, traffic forecasts in the context of port planning and development are inherently dependent on the assumptions and scenarios which PAs formulate (Zhang et al. 2013). 
The uncertainty level is partly the result of high levels of variability and seasonality in traffic flows caused by economic cycles (peaks and downturns), seasonal fluctuations and time variations (Stopford 2009; Farhan and Ong 2018) and economic, social, political, nature-related or health shocks and crises. The port choices made by (large) market players such as shippers, shipping lines and related carrier alliances can also generate traffic volatility. Actors' port loyalty and differences in perceived port switching costs make that some supply chains and related cargo flows are more prone to shifts between ports. For example, Notteboom et al. (2019) demonstrate that traffic volatility in container ports is particularly high in sea-sea transhipment flows. The existence of high and often rather random traffic volatility makes traffic forecasting even more difficult.

Port services demand is considered a "derived demand", as it originates from shipping lines' service patterns which, in turn, depend upon a number of underlying macro- and micro-economic variables. Often these variables are also characterized by causal relationships which increase technical concerns related to the selection of the most suitable statistical methods for predicting future traffic flows. This further adds to the uncertainty and complexity of forecasting exercises in the port domain (Rashed et al. 2017).

Uncertainty in future demand also originates from the fact that port facilities are highly dependent on what happens in the global transport and logistics networks of which they are part. The demand for port services is affected by evolutionary trajectories of other infrastructures connected to the port and the transport routing choices made by actors in global supply chains (Haimes and Jiang 2001; Notteboom and Rodrigue 2009). For example, the launch of the Belt and Road Initiative (BRI) in 2013 has given impetus to the large-scale development of scheduled rail freight services between China and Europe with impact on routing decisions of shippers and logistics service providers.

Finally, traffic forecasting in port planning and development typically assumes a mid- or long-term perspective. These predictions have to cover a potentially broad timeframe, which could range from 5 to 30 years. This further exposes forecasts to some bias which may arise from apparently minor errors in the selection of data and information or methods of statistical modelling.

\subsection{Traffic forecasting as part of port planning and development}

Traffic forecasts are often part of strategic seaport planning exercises or port master plans (Coeck et al. 1996). The realization of port infrastructures requires large amount of financial resources and a proper endowment of technical and organizational skills (Satta et al. 2017). In such circumstances, port planning becomes a complex analytical work aimed to matching cargo flow projections and future demand estimations with the development and acquisition of suitable infraand super-structures. PAs are expected to attract the interest of private partners for co-financing, developing and running new terminal and logistics facilities. The undertaking of sound forecasting activities by PAs should unveil future market opportunities in various maritime business segments and facilitate a smooth 
allocation of technical and financial resources to the new ventures. While PAs generally undertake planning initiatives in the area of port development, a port's supervisory authority (ministry/region) usually decides on the actual implementation by approving or disproving "Port Development Plans" submitted by the PA.

Notably, port choices incorporated into master plans and related official documents are often made in an attempt to balance the conflicting interests of different stakeholders. Several port investment decisions, therefore, can be triggered by political, social or strategic reasons, without proper in-depth analyses and future demand projections. Nonetheless, port managers are increasingly expected to rely on forecasts and other statistical or quantitative techniques for supporting and justifying the entire decision-making process related to port planning and development. As the diffusion of public-private partnerships calls for higher transparency, especially during concession awarding procedures and negotiations between public parties and private bidders (Pallis et al. 2010), PAs are required to disclose more information on the assumptions which underlie their strategic planning. This allows them to strengthen the reliability of their development plans. For these reasons, the analysis of PA planning activities and the evaluation of forecasts reported to the market and relevant stakeholders shed light on the state of the industry. In addition, the duty and accountability of disclosing information to stakeholders are increasingly seen as a common obligation for port managers to satisfy new laws and regulations (Parola et al. 2013a).

When focussing on continental European ports, where the landlord model is the dominant paradigm for governance settings, it becomes evident that PAs show rather heterogeneous approaches to strategic planning and traffic forecasting. Tables 2 and 3 describe the attitude of 28 PAs toward forecasts in strategic port planning. The selected PAs belong to the EU Core Port Group, a shortlist of over 80 ports, which are part of the so-called core network within the European Commission's TEN-T blueprint [see Regulation (EU) No. 1315/2013 on the trans-European transport network]. The 28 PAs have been selected for in-depth analysis of their disclosure behaviour related to forecasts for port planning purposes, as they report on their respective websites at least one reference to their port planning activities. The sample of ports covers 16 countries. For the aim of the study, we screened website contents with a specific focus on published statistics and historical traffic data and corporate documents (e.g. Master plans, annual reports etc.).

In the past two decades, a growing number of PAs have initiated comprehensive processes of long-term strategic planning, along with a more conscious and analytical perspective on the modelling of port expansion programs, also making traffic data and forecasts available to stakeholders. In this vein, for example, PAs started to disclose their annual reports and related statistical information since 2005, on average. However, the examined PA planning documentation and website contents unveil important differences in their strategic behaviour. Five groups of findings are presented in the next sections. 


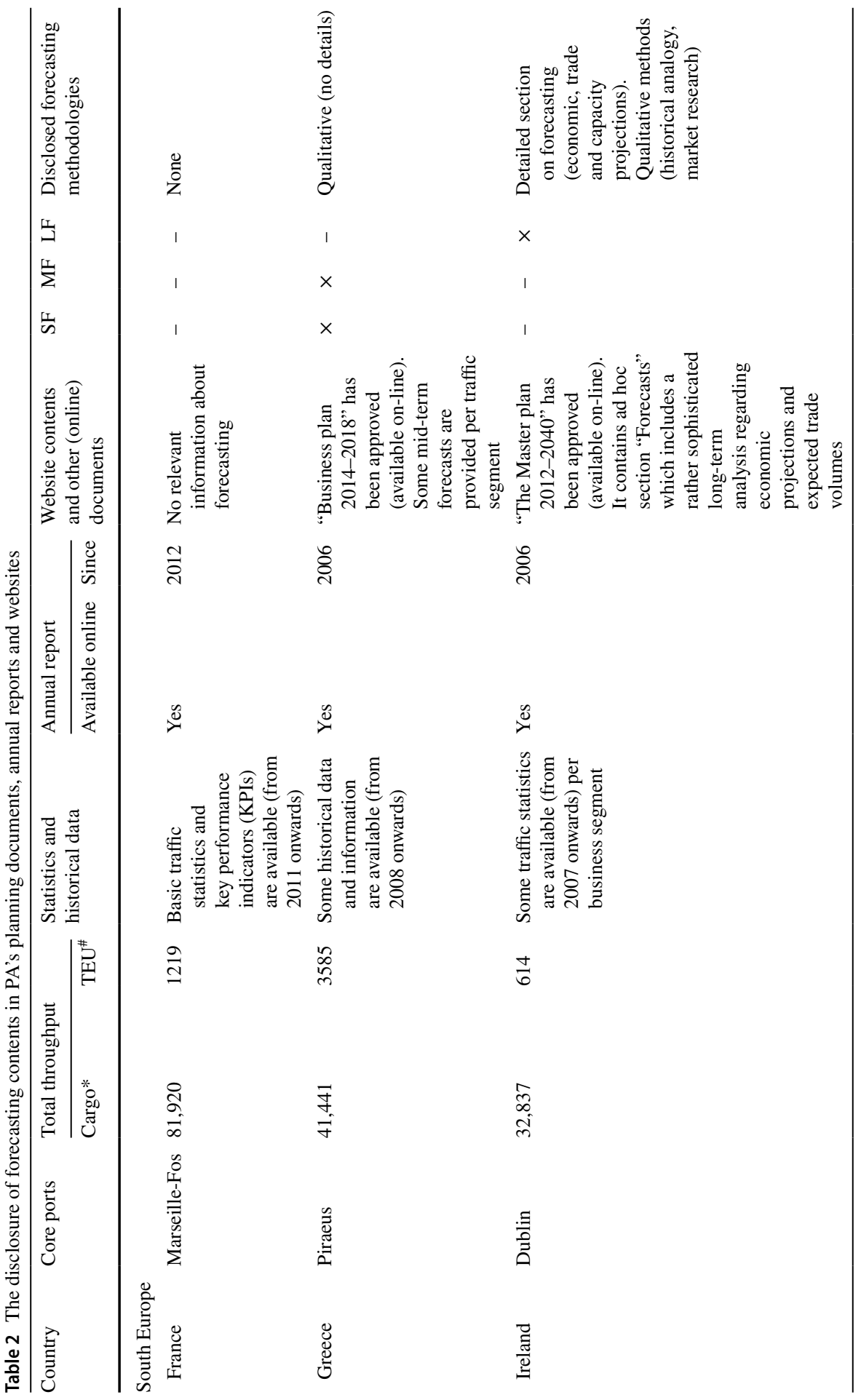




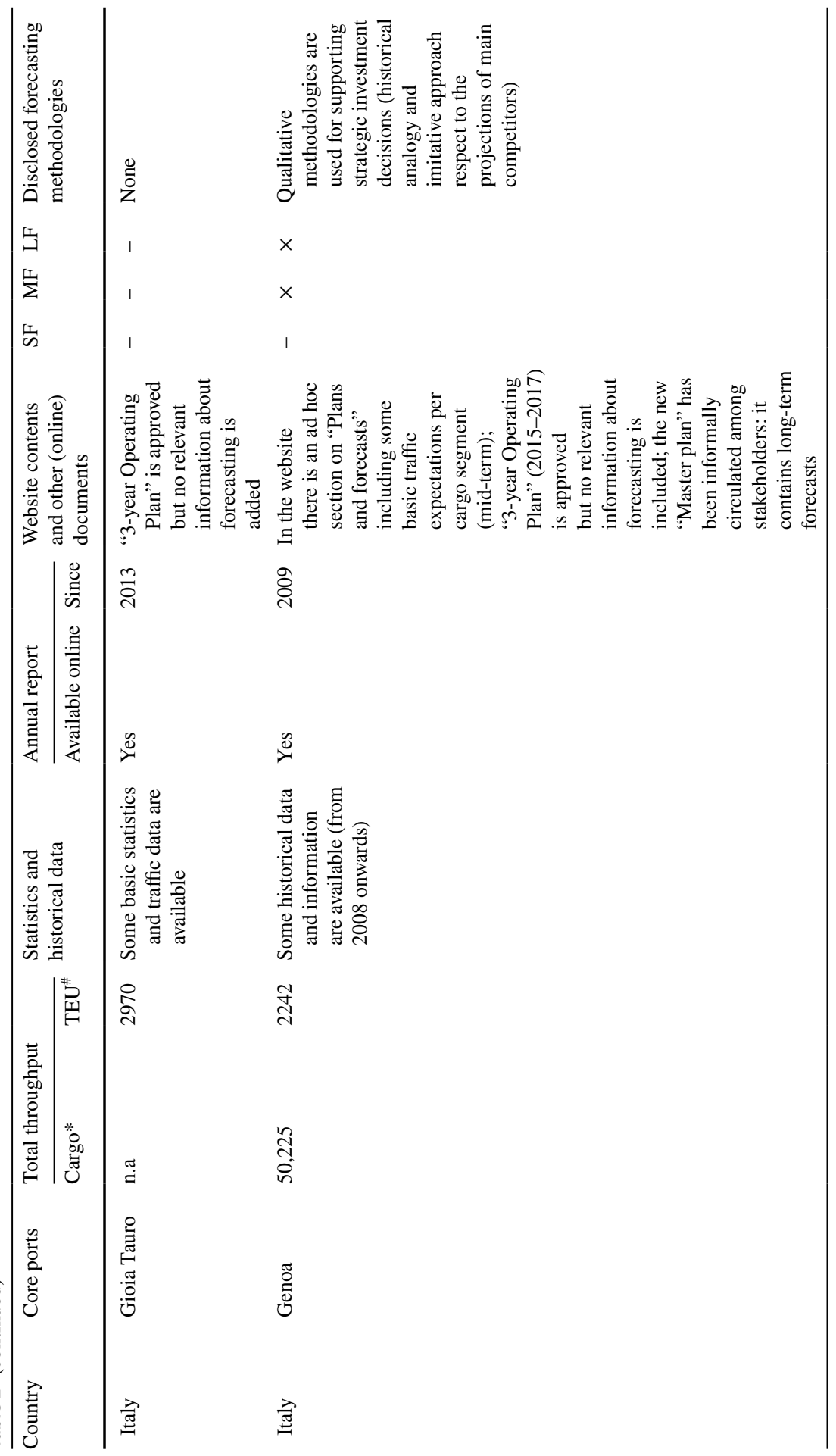

我造 


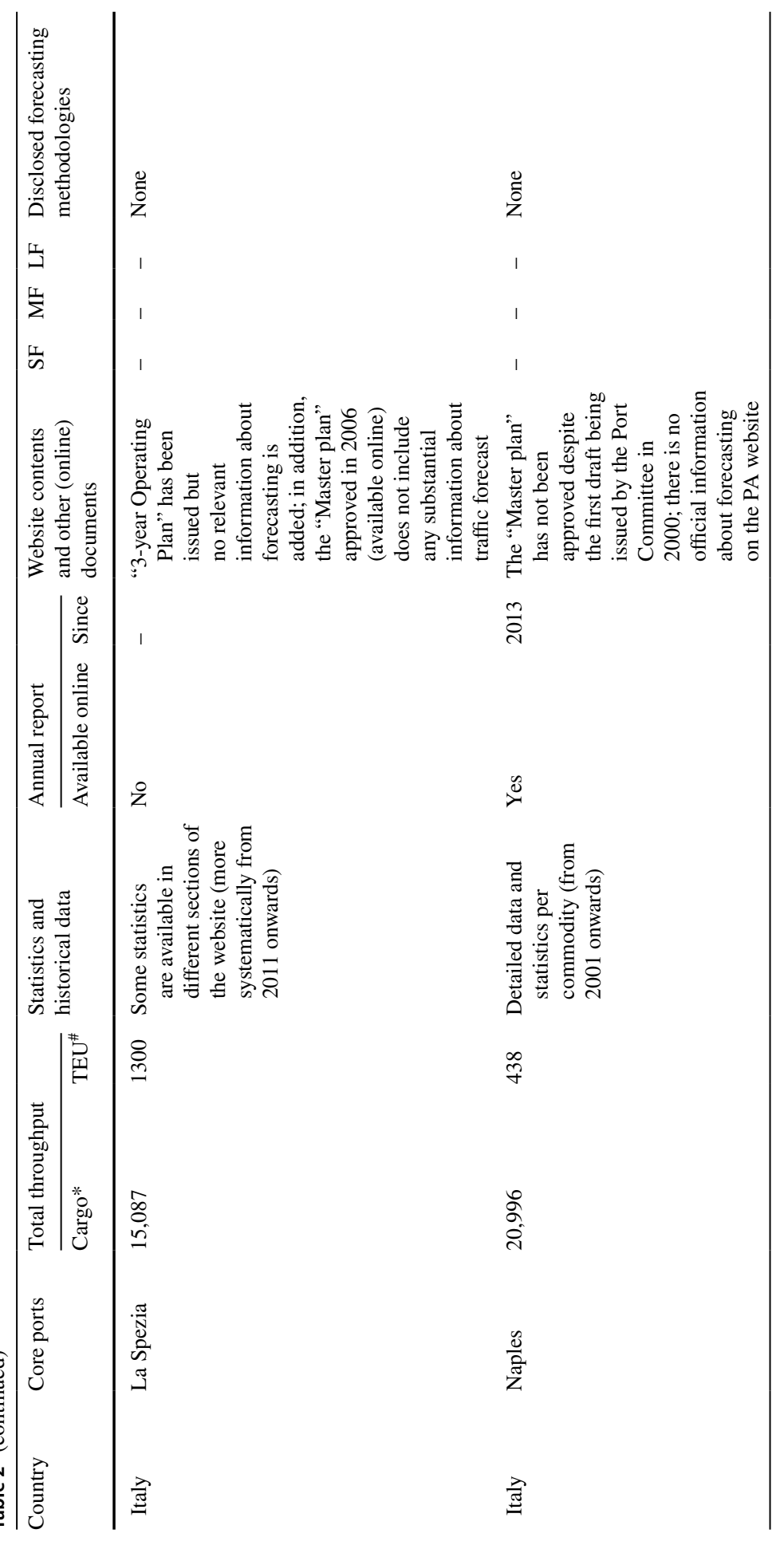




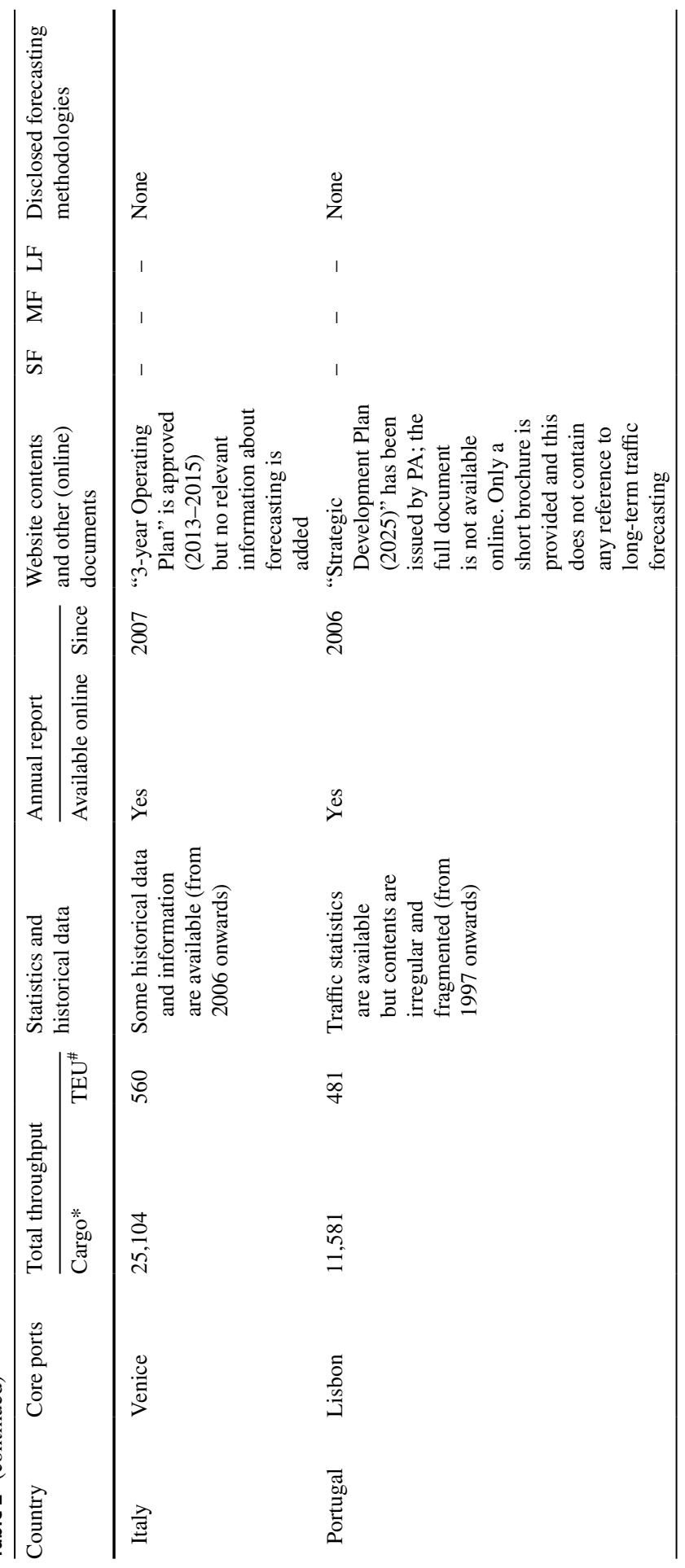

s. 


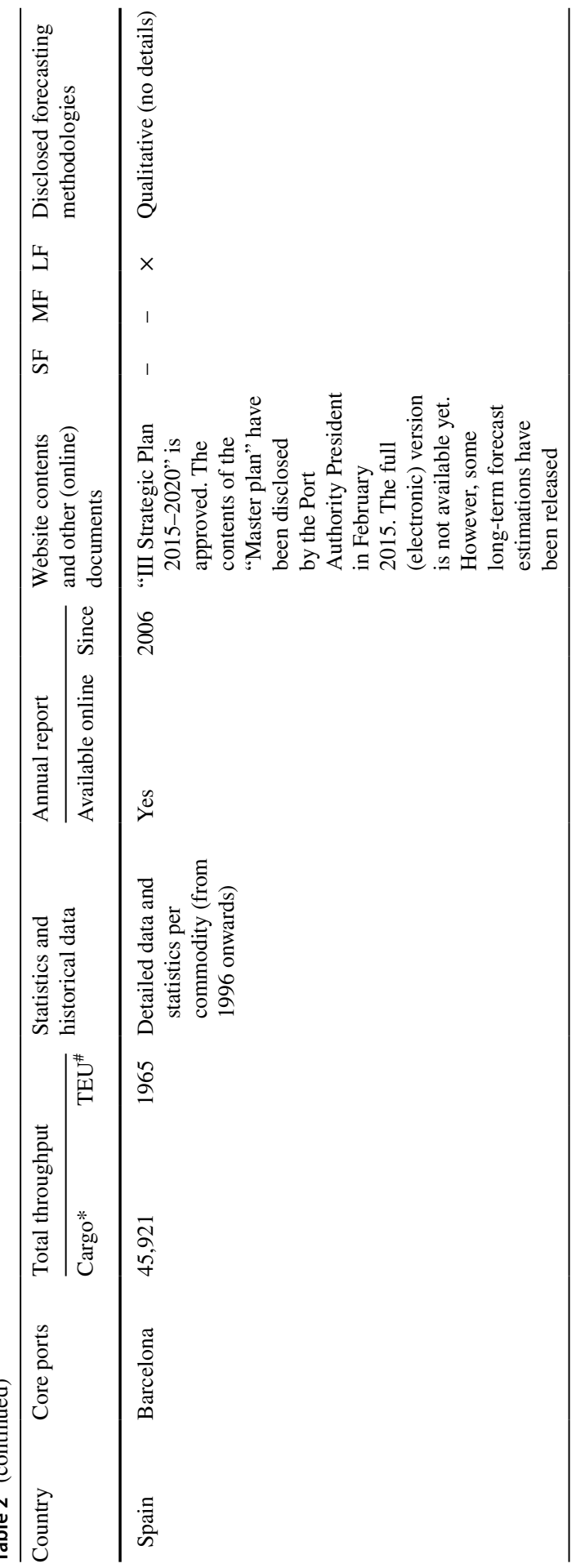




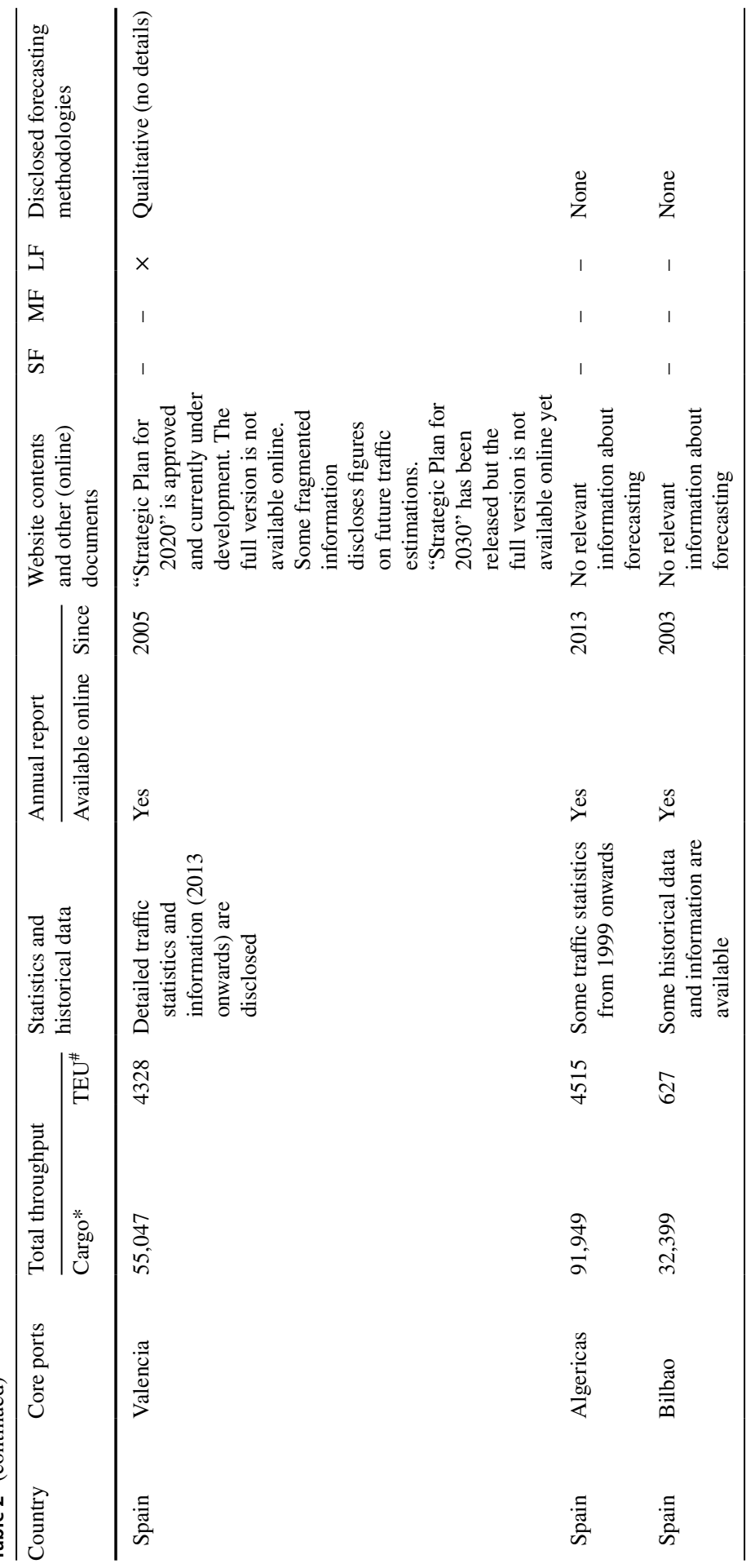

称。 


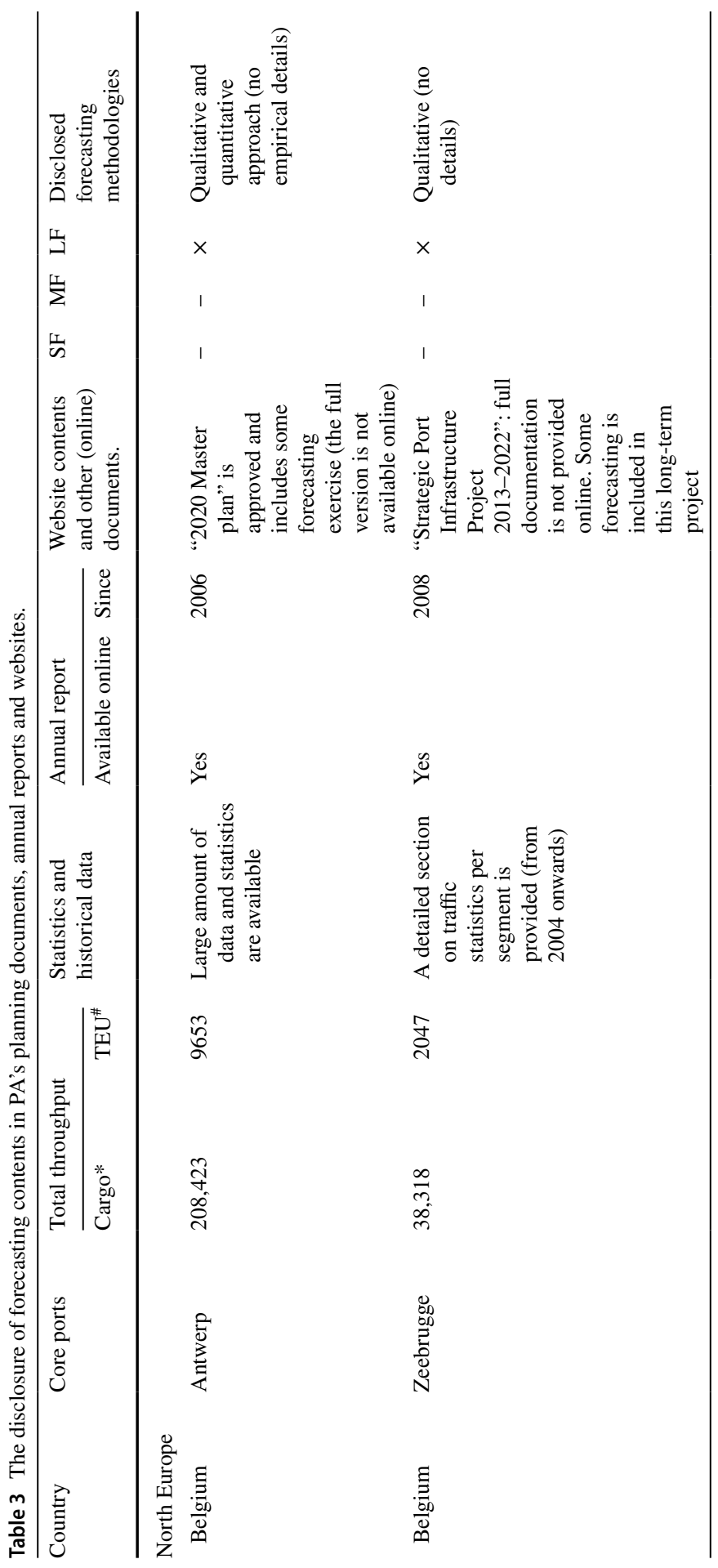




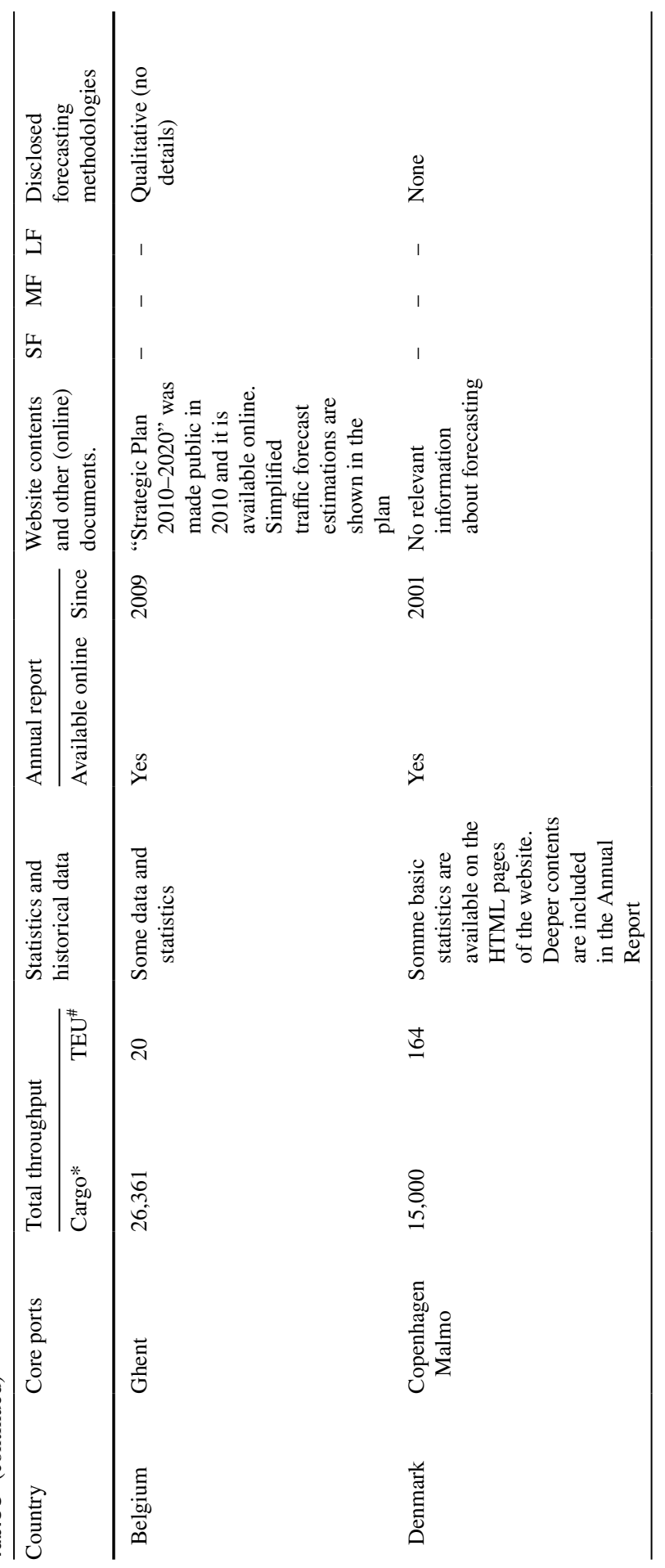

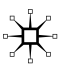




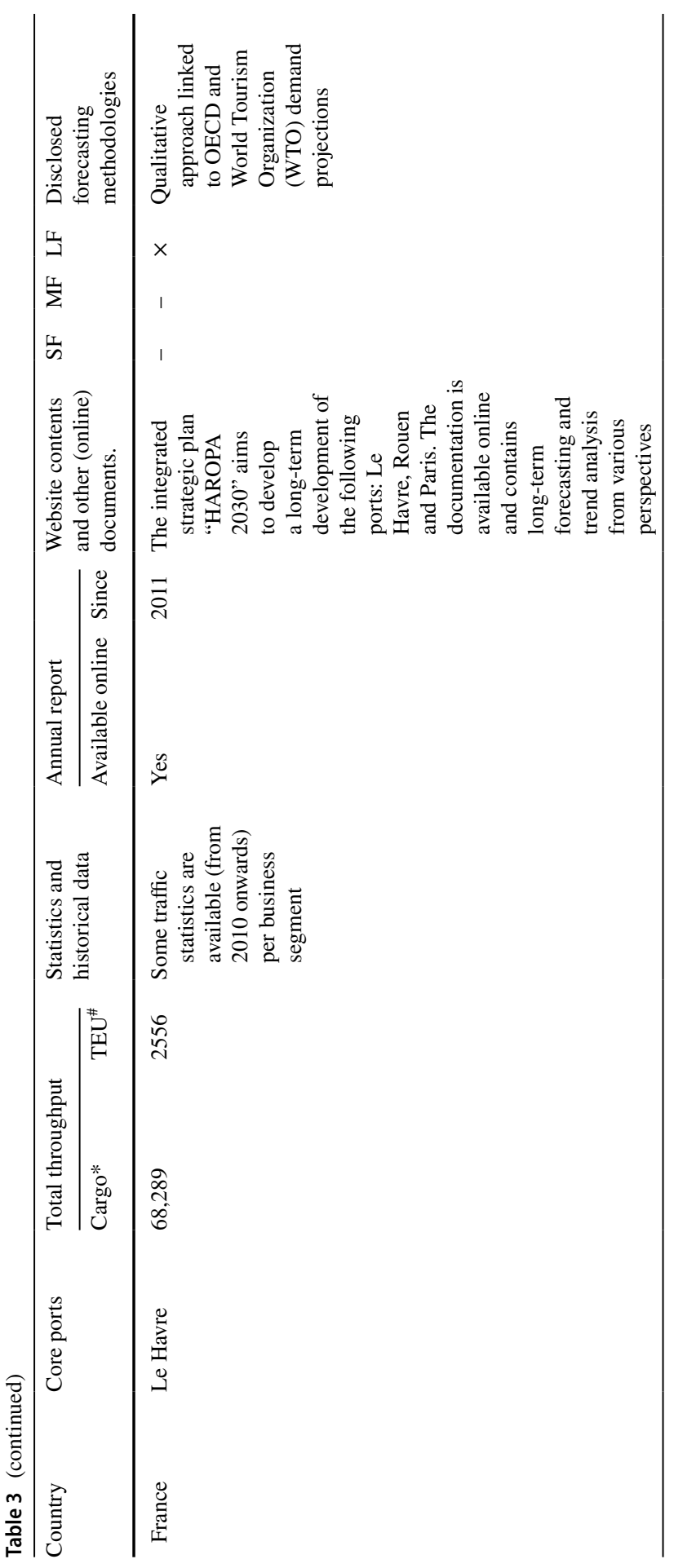




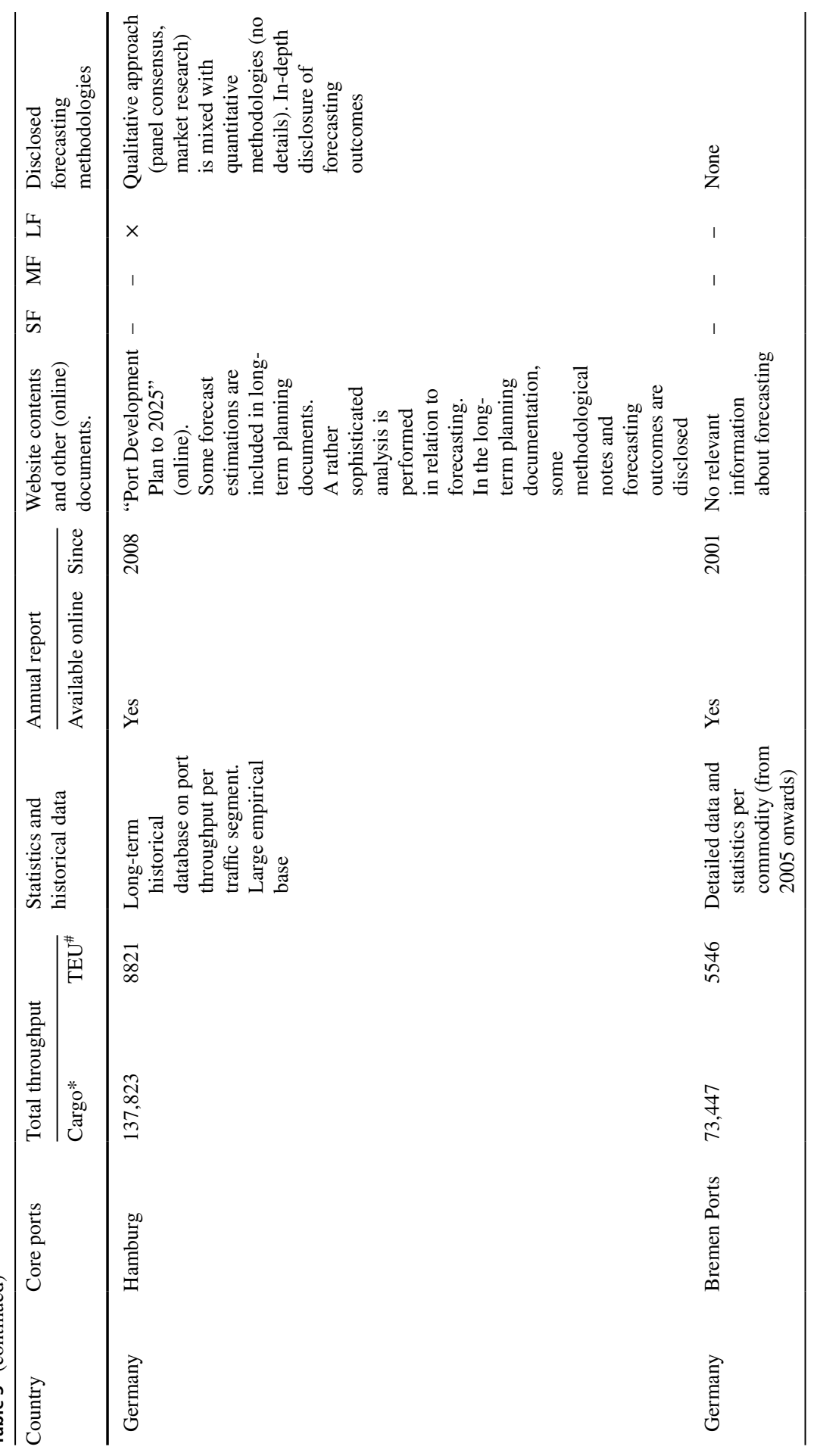

站 


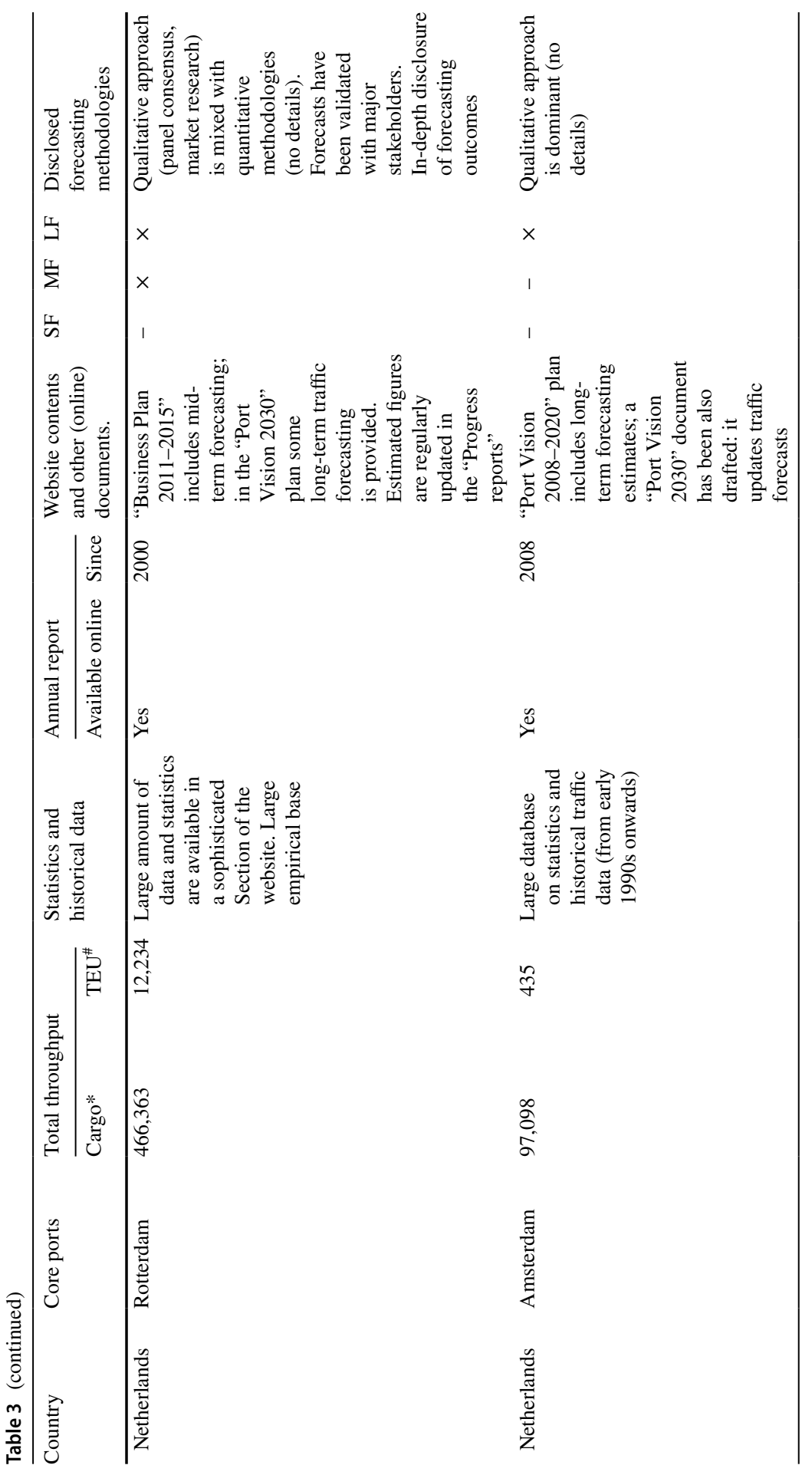




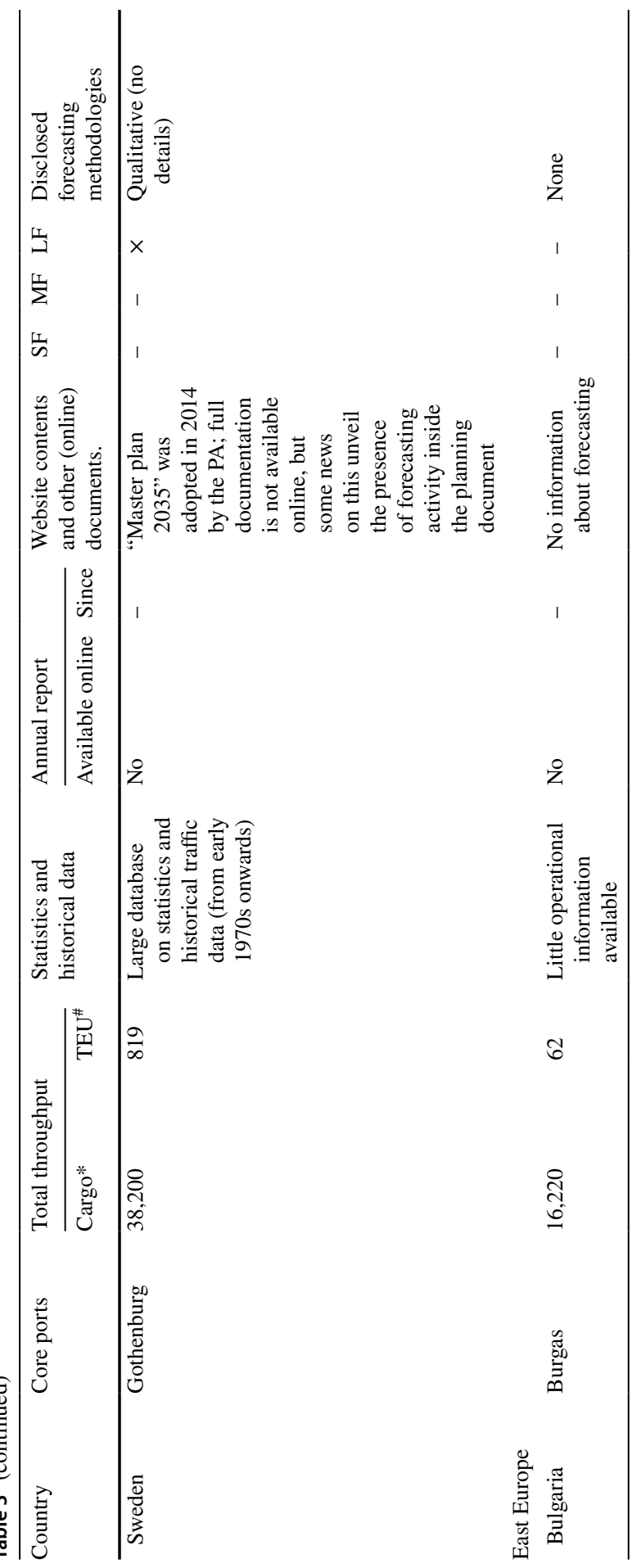

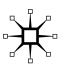




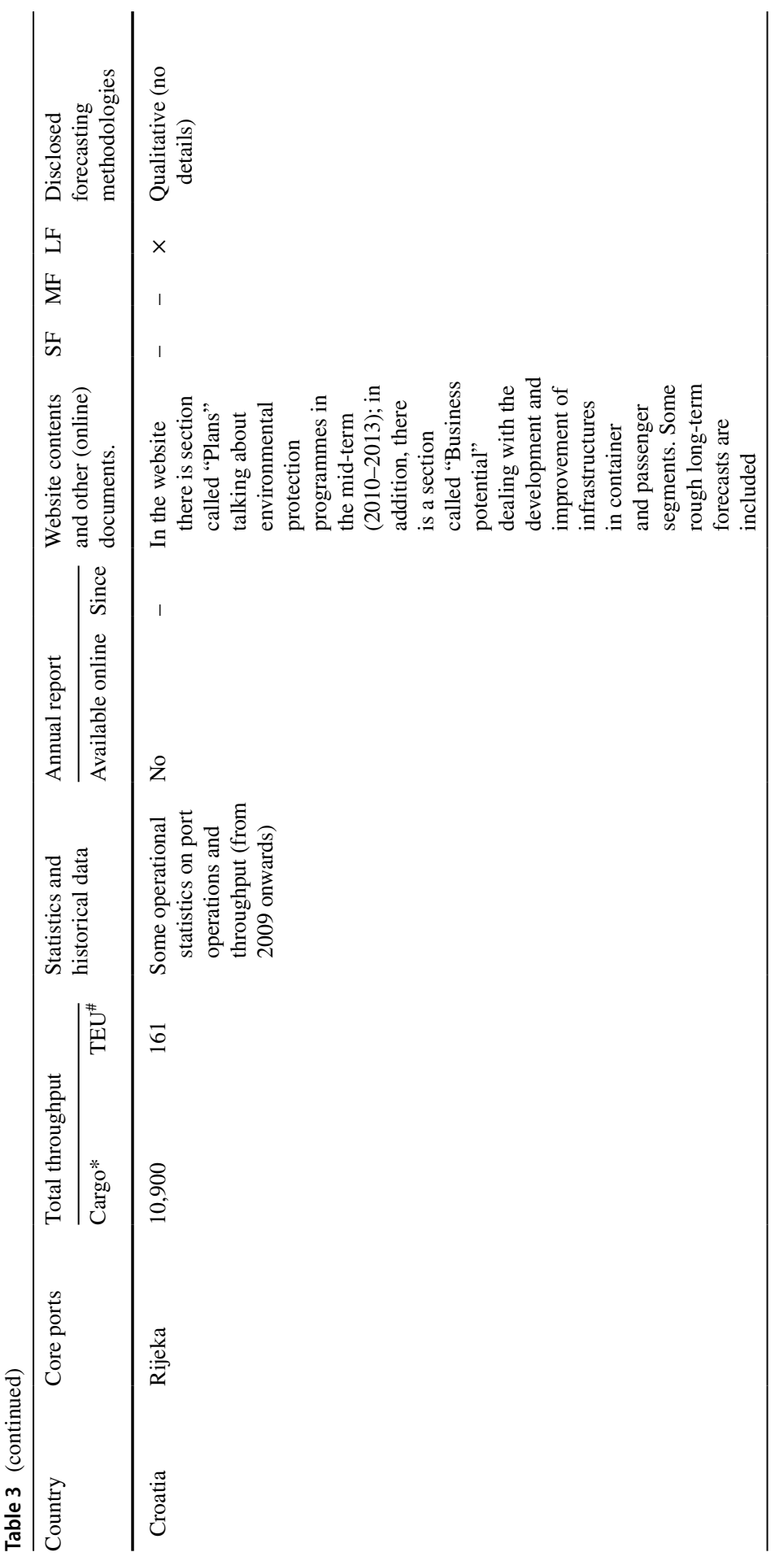




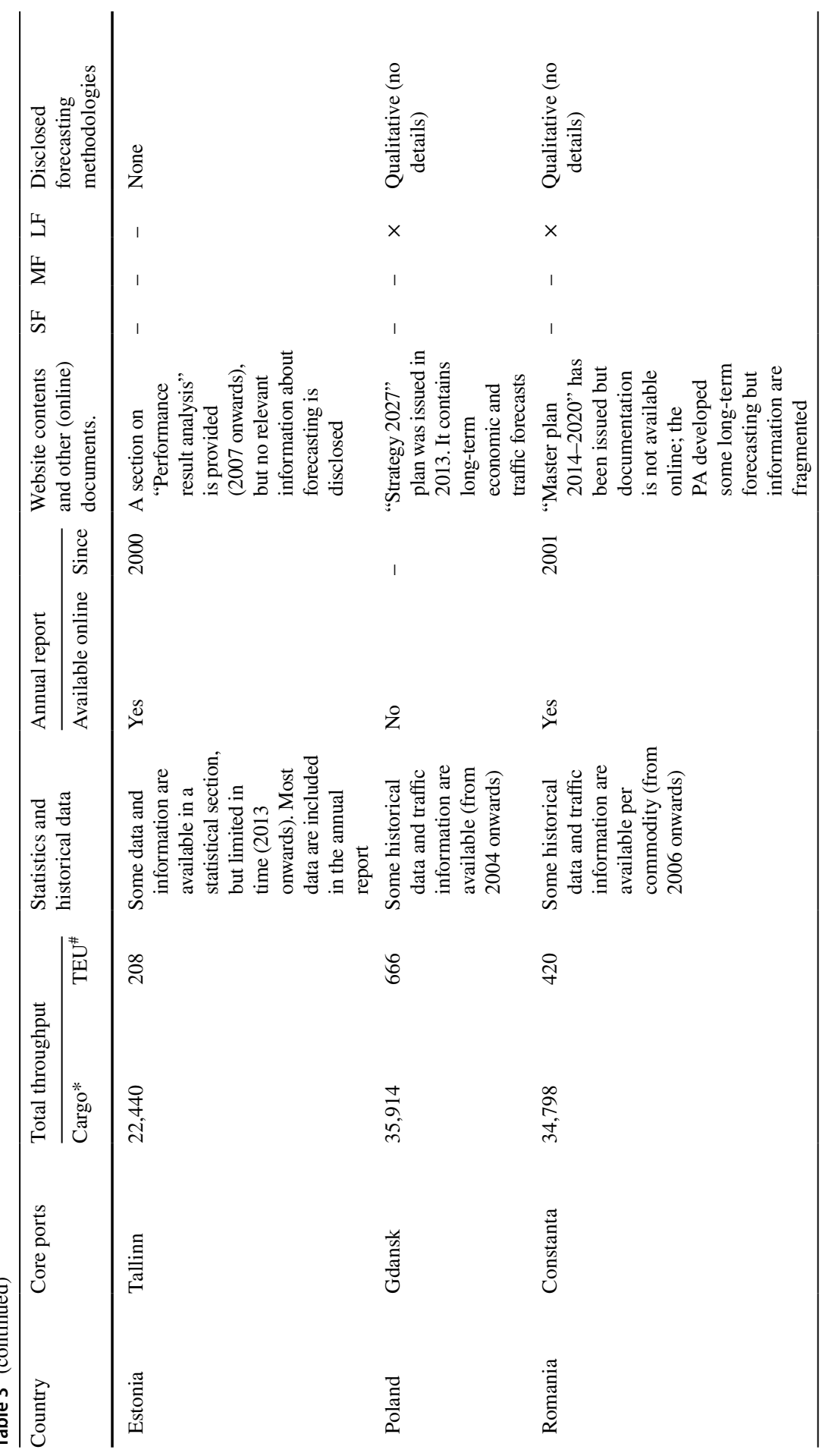

站 


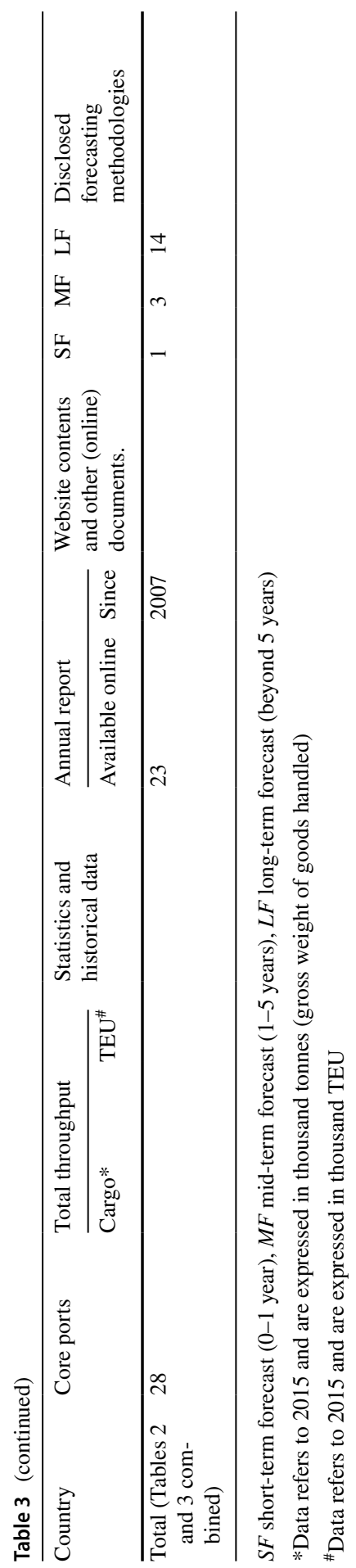




\subsubsection{Formalized planning versus ad hoc investment decisions}

A growing number of PAs develop formalized and well-established planning documents. The best practice can be found in the Port of Piraeus, which provides a business plan including short- and mid-term forecasting, as well as the Spanish ports of Barcelona and Valencia, which approve their strategic plans based on longterm forecasting exercises. Similarly in Northern Europe, the Port of Rotterdam and the Port of Hamburg are among the top players in terms of presenting planning documents. The former has issued a "Port Vision" with a long-term perspective and will implement it through a 5-year business plan; the latter port provides only the "Port Development Plan" to 2025, including a rather sophisticated forecasting analysis with in-depth methodological notes.

Still, quite a number of ports, particularly medium-sized and minor ports, continue to operate on an informal or fragmented basis. Development in these ports often lacks a common backbone, being the result of the evaluation of ad hoc opportunities or political/market pressure. In these cases, port planning activity is not formalized into a comprehensive planning document with a long-term focus. Thus, some PAs opt for fragmented planning approaches and rather ad hoc expansion programs which increase port capacity incrementally instead of in large steps. In other words, some PA investments in specific business areas appear to be triggered by favourable demand forecasts, resulting in ad hoc actions which capitalize on emerging "windows of opportunity" and "critical junctures" (Jacobs and Notteboom 2011) not adequately supported by scientific methodologies. PAs might also rely on imitation or a herd behaviour strategy by following the mainstream actions and expectations of the closest competitors. This myopic way of conceiving port planning can lead to inefficient and sub-optimal solutions. Thus, the degree of sophistication and the level of disclosure of planning documents are affected by PA's approach towards strategic decisions.

\subsubsection{Types and time horizons of port planning documents}

The available port planning documents come in various forms and differ in terms of temporal perspective and nature (e.g. short-, mid- or long-term oriented; stand-alone versus updating documents; strategic versus tactical documents). With regard to the temporal perspective, long-term planning largely dominates (14 cases out of 28). Quite often, the same PA develops a two-tier planning activity based on documents addressing different time horizons. Consequently, planning documents have various structures and contents.

Port planning and development exercises typically rely on longer term forecasts. A long-term perspective in ports is often assumed to have a time horizon of at least 5 years. For example, a 15-30 year perspective is reasonable when evaluating port investments and concessions (Parola et al. 2013b) and when developing strategic port plans or master plans (Coeck et al. 1996). In port-related forecasts, the time horizon can influence the selection of the proper forecasting techniques. Long-term predictions are based either on the extrapolation of mega trends or on analogies, making time series analysis an optimal methodology for addressing this 
type of issue. Nonetheless, the longer the time horizon of predictions, the lower the expected accuracy of forecasts. The purpose of port-related forecasting in such circumstances is often to build scenarios that help port managers and decisionmakers to identify the major opportunities and threats going forward, and to deal with related uncertainties. Strategic port planning by PAs is to be considered as a continuous process that assesses all relevant parameters and interrelations and "models" uncertainty via sensitivity analyses and scenario building.

\subsubsection{Forecasting methods and data sources}

Several forecasting techniques can be potentially applied to deal with the complexity of forecasting problems in port planning and development. A number of factors may affect the selection of the most appropriate method: i.e. the context of the forecast, the relevance and availability of historical data, the desired degree of accuracy, the time period to be forecasted, etc. (McCarthy et al. 2006).

There are two basic types of forecasting methods found in academic literature: qualitative and quantitative. Quantitative estimation techniques are based on series of historical data, allowing to establish trends and relations among dependent and independent (explanatory) variables. These relationships are subsequently used in forecasting future values.

A first set of quantitative forecasting techniques is based on time series analysis. In these models, the expected future value of a variable, i.e. port throughput, is obtained by extrapolation or mathematical deduction from the historical pattern of the variable concerned. Scholars also make a distinction between parametric versus non-parametric forecasting models (Farhan and Ong 2016). The most used are moving average and exponential smoothing, ARIMA (autoregressive integrated moving average) approach, considering or excluding seasonality (SARIMA, X13ARIMA-SEATS), as well as additional implementations and generalizations (e.g. ARCH and GARCH models etc.). To overcome the linearity assumption of data generating process, artificial neural network (ANN) and smoothing splines models are also suggested by academics (Ripley 1994).

A second set of more sophisticated quantitative forecasting methods rely on both causal relationships and time series analysis. Causal models aim to capture relationships among variables by mathematical expressions, which constitute the starting point for scenario-based forecasting. A large set of econometric models have been implemented (e.g. OLS, GLM, multilevel or hierarchical modelling etc.), supported by longitudinal time series data (Parola and Sciomachen 2009).

When data are scarce or ambiguous, qualitative forecasting techniques are preferred. These typically rely on expert human judgements and opinions, combined with non-complete and/or non-numerical data. Qualitative forecasting techniques include explorative and normative techniques. In explorative methods, future developments are evaluated on the basis of empirical data from the past, supplemented by expert information regarding the expected traffic flows (see e.g. Xiao et al., 2012 and De Langen et al. 2012). Normative techniques start from future objectives and try to assess whether these objectives can be met, taking into account the present resources, capacity, structural limitations and technologies. Among these 
techniques, expert opinions are used in the Delphi method, panel consensus forecast, and visionary forecast. The market research forecast and historical analogy forecast are based on both expert opinions and knowledge of general trends. In general, qualitative methods are useful for drawing approximate scenarios in a highly volatile context. In the port domain, these methods are expected to support managers when decisions are taken in complex environments or when several variables characterized by high volatility affect predictions (Tian et al. 2013). Furthermore, qualitative methods are supposed to be preferable in supporting investment project selection based on heterogeneous assumptions about competitive and market conditions. Hybrid methods that combine qualitative and quantitative approaches can also be deployed in traffic forecasting.

Reliable forecasts depend on high quality data. Primary data originate from surveys, interviews and direct observations; secondary data include government information, official statistics and administrative data. Compared to primary data, secondary data tends to be readily available and inexpensive to obtain. In addition, administrative data tends to comprise large samples and they are collected over a long period of time. Data quality matters, i.e. the accuracy and reliability of the gathered information, as well as the identification of the main sources of error (sampling and non-sampling errors), the evaluation of potential bias and outliers as well as missing data treatment. Moreover, high quality data have to be internally consistent and coherent. They also need to be comparable over time and between regions or countries (Satta and Persico 2015).

Nonetheless the gap between academia and the industry clearly emerges when scrutinising the attitude of PAs towards traffic forecasting and related methodologies, as well as their willingness to disclose sensitive information regarding the decisionmaking process on which port planning and development is grounded.

\subsubsection{The attitude towards the disclosure of traffic forecasts and methods used}

The researched planning documents unveiled rather heterogeneous attitudes of PAs to the voluntary disclosure of the contents and outcomes of their forecasting activities (Tables 2, 3). Basically, Mediterranean PAs are less prone, compared with northern range ports, to resort to forecasting techniques to support their investment decisions. The release of information concerning forecasting techniques and data input (when applied) provide insights on the reliability of long-term strategic objectives.

PAs show differences in terms of willingness to disseminate information about planning or forecasting studies. Although the majority of the sample PAs (23 out of 28) disclose their annual reports online, only some PAs, like Rotterdam, Hamburg, Dublin, Amsterdam, Piraeus and Valencia extensively communicate detailed statistics or time series on traffic data, and make their estimations of economic and demand growth publicly available via their website or publicly accessible reports. Conversely, a number of PAs report a minimum amount of historical data and do not provide any information on planning and forecasts on their website. Data and information on short-term forecasting are even more rare. While 14 PAs provide information related to long-term forecasts, only three port managing bodies disclose 
short- and/or mid-term statistical projections related to throughput (i.e. Rotterdam, Piraeus and Genoa). The lack of transparency resulting from a non-disclosure of forecasting data (which underlies decisions on public investments) is a critical concern in PA management and planning.

Despite the complexity in the drivers of port traffic volumes and an increased academic focus on advanced and hybrid approaches to traffic forecasting (see discussion above), not all PAs prefer the use of cutting-edge forecasting methods, even if these could provide better results. This attitude does not imply PAs are generally not aware of the existence of advanced forecasting techniques and methods. Instead, a PA might fear that the use of complex methods gives the forecasting exercise a high "black box" image to stakeholders. If the PA or their experts fail to provide full details on how the forecasts were produced, the validity of the whole exercise could be questioned by one or more stakeholder groups. Other PAs are reluctant to provide non-mandatory information on this topic and prefer to maintain some information asymmetries (Trujillo et al. 2002). PAs might even prefer the use of very advanced forecasting methods if they feel they have real value, but also because the related forecasts have a higher chance of being taken for granted by stakeholders who dare not to challenge the "rigorous academic" outputs of the forecasting experts. All these matters might not make PAs very inclined to disclose information about the methodologies applied to obtain forecasts.

In general, the application and disclosure of qualitative methods largely prevails on the use of quantitative techniques. Typically, PAs refer to broadly recognizable data sources for their demand/throughput estimations, including, among others, OECD, World Trade Organization (WTO) and World Tourism Organization. As mentioned above, qualitative methods are more "accessible" and understandable by stakeholders, and they also require a lower amount of data input. In order to build a more solid consensus around forecasting (and planning), PAs often resort to the informal validation of preliminary projections by major stakeholders. Sixteen of the sample PAs adopted qualitative methodologies for making forecasts and, some of them (e.g. Dublin, Genoa, Rotterdam, Le Havre and Hamburg), explicitly refer to specific techniques, then validating their outcomes often considering analogies with the forecasting approaches adopted by competitors. In addition, some PAs support their planning decisions also on the implementation of quantitative techniques, for corroborating the more diffused qualitative methodologies. This is the case for the top three EU ports, i.e. Rotterdam, Antwerp and Hamburg, which adopt mixed forecasting methods. Indeed, no PA discloses detailed information regarding the quantitative statistical techniques applied in master planning.

\subsubsection{Institutional issues affecting traffic forecasting exercises}

Institutional issues, particularly governance-related aspects of port planning, can have an impact on the role and technicalities of the traffic forecasting exercises.

First, several public and private actors involved in port planning and development are expected to incorporate forecasts in their planning and decision-making processes. Among the public actors, PAs need to develop accurate and reliable long-term predictions in order to support port planning and development and or 
manage inter-port competition (Taneja et al. 2010). Major PAs often form dedicated port planning teams in which experts are responsible for the forecasting activities. In ports with a smaller traffic size or limited in-house forecasting experience, PAs normally resort to external advisors for the development and application of appropriate forecasting methodologies. The absence of a dedicated pool of skills on these topics can negatively affect the outcomes and the disclosure of forecasting exercises and can lead to difficult content-related discussions between the experts and PA representatives.

As long-term forecasts may affect competitive bidding procedures in the field of terminal concessions and leases, information asymmetries may emerge, and the development of knowhow is fundamental to avoid bias or voluntary human errors in this field. Several authors, for example, point out that PAs tend to overestimate longterm traffic forecasts in view of obtaining higher investment volumes (Lam et al. 2004). Analogously, private terminal operators involved in concession procedures may present overly optimistic long-term traffic expectations in order to outperform other bidders or to obtain favourable concession conditions (Trujillo et al. 2002; Kulkarni and Prusty 2007; Cruz and Marques 2012). Other public actors involved in port forecasting include policymakers and regulators. Among private parties, terminal operators, investors and financiers, as well as specialists and analysts, are expected to be exposed to the risk of biased port traffic forecasts.

Second, port governance management models and cultural dimensions might influence the PA's attitude towards the disclosure of forecasts supporting port planning processes. In particular, data reported in Tables 2 and 3 and distributed per port region reveals that PAs from Northern Europe following the "Hanseatic" tradition of port governance (see Verhoeven 2010 for the terminology) demonstrate more experience in the use of forecasting tools and a well-rounded attitude in terms of the disclosure of these forecasts. Conversely, the dissemination of data and information on port planning and forecasts is not common for PAs in Eastern Europe. South European ports following a more "Latin" approach in port governance show mixed results: only 5 out of 13 ports disclose forecasting data.

Third, master planning in some ports turns out to be a very tedious and timeconsuming exercise involving many national, provincial and/or local authorities. As it may take many years to complete a master plan, some of the initial assumptions and forecasts might already be outdated by the time the plan is presented. This can undermine the validity of the master plans and open a window of opportunity for decision-makers to justify their actions related to certain port investments on other grounds than the master plan provisions.

Finally, the approach to port planning and traffic forecasting can be influenced by the management approach in place. Bower (1983) distinguishes between two management systems: a political and a technocratic approach. PAs relying on a technocratic management style focus on efficiency and pursue clear objectives such as profitability or regional economic growth. In such an environment, strategic port plans and associated forecasts can be instrumental in laying out a path towards meeting the port's objectives or overall mission statement. A political management system rests on the principle of equitable and legitimate distribution of costs and benefits to which there are common claims. Ports that follow the political management 
approach generally have more diffused goals and do not always use clear decision criteria for allocating resources. These ports often work in an environment of elected or politically appointed controlling boards. The port development path is shaped by administrative heritage and structural shocks caused by powerful individuals or pressure groups, which leaves less room for using extensive formal and objective port planning processes to adequately adapt to structural changes in the port's environment. In practice, the divide between political and technocratic approaches in ports is not always clear (Notteboom and Winkelmans 2001). As technocratic PAs are, to some extent, dependent on political organizations for their survival, it is often difficult to exclude some level of politicization of an efficiency-driven management system, particularly since ports are strategic assets for community welfare creation.

\section{Conclusions}

This paper contributes to the extant debate on port planning and forecasting by analysing current approaches and challenges for academics and port authorities with respect to traffic forecasting in a port planning and development context.

The literature review revealed that traffic forecasting is a rather small academic research field in port economics and management. Qualitative and quantitative methods can be equally viable options to produce long-term traffic forecasts in a strategic port planning context. Qualitative methods include Delphi method, market research and scenario-based forecasts. As uncertainty over explanatory variables is a serious concern in long-term forecasting, qualitative scenario-based analysis is seen as a viable tool for investigating the impact of economic and transport trends on future trajectories in cargo throughput.

In the quantitative field, advances have been made in both time series analysis and causal models applied to traffic forecasting, with neural network models appearing more accurate than regression analysis. However, neural network analysis is demonstrated to be rather time-consuming, requiring the gathering of heterogeneous data inputs. Lack of human and financial resources may be obstacles to the adoption of complex quantitative forecasting techniques in port planning and development. More recent academic contributions compare or combine various forecasting methods and techniques, particularly by proposing a mix of quantitative and qualitative methods. To better deal with disruptions and trend breaks, hybrid approaches have emerged which rely on expert information and judgement to complement the outputs of quantitative traffic forecasting models.

More disaggregated traffic forecasting is used to generate specific commodity insights. The analysis of the methods and techniques used by PAs revealed that qualitative approaches are dominant, and in the few cases where PAs claim to utilize quantitative methodologies, no empirical details are disclosed in master/ strategic plans. Indeed, PAs prefer to keep hidden the statistical techniques applied to shape demand forecasts, although sometimes stakeholders' validation (e.g. panel consensus, in-depth interviews etc.) is informally performed to adjust preliminary demand projections. This demonstrates the existence of a rather profound "methodological gap" between the approach typically undertaken by PAs and the 
most diffused quantitative statistical techniques applied by scholars in academic research. Especially for top-rank ports, the introduction of more transparent forecasting exercises would be desirable, as well as introducing more explicit and sophisticated empirical methods which have been already applied in other industries.

Major PAs often form dedicated port planning teams which are also responsible for the forecasting activities. In ports with a smaller traffic size or limited in-house forecasting experience, PAs normally resort to external advisors for the development and application of appropriate forecasting methodologies. Complex forecasting methods might not be used even if these would provide better results. This does not necessarily mean the PA cannot mobilize skills or competencies to apply advanced forecasting techniques. Instead, a PA might fear that the use of complex methods gives the forecasting exercise a high "black box" image to stakeholders, therefore potentially hampering discussions with them.

Both the literature review and the empirical evidence obtained from our sample of EU core ports demonstrate that the selection of a forecasting technique does not only depend on the temporal horizon assumed in the analysis but also on other analytical contextual dimensions. In this vein, ad hoc forecasting methods and models, for example, should be implemented for each type of variable. This approach is not always feasible, especially when port managers and policymakers have to deal with numerous relevant indicators or variables. Nonetheless, the application of advanced techniques is recommended. Port cargo throughput and container throughput emerge as the highly relevant variables to assess, due to their role in shaping port planning and development.

An examination of the behaviour of European PAs demonstrates that different attitudes towards forecasts by port managers may be triggered by several exogenous or endogenous variables. Among them, both port size as well as institutional and port governance settings are suggested to be valuable predictors of a PA's attitude towards forecasting and the disclosure of the associated statistical exercises. Larger PAs, particularly in Northern Europe, embrace forecasting tools to support future investment plans and decisions. They also publicly disseminate major information related to the forecasting exercises. Conversely, small PAs and authorities located in Eastern European countries still rely on less sophisticated approaches. They are invited to reinforce the nexus between strategic forecasting and planning to support port development and attract additional private financial resources.

The disclosure of statistical assumptions and methods underlying the development of forecasts used in port planning and in port concession procedures is expected to increase transparency in awarding procedures, to improve the effectiveness of the evaluation process as well as to ensure high-quality monitoring in the post-bidding phase. PAs, in particular, are invited to request specific data and information from private bidders regarding the assumptions and the estimations used in their forecasting exercises that support business plans. Thus, the results may foster PA's decisions in public-private partnerships (PPPs), thereby guiding negotiations with private operators in terms of concession duration and pricing/fees issues.

When it comes to regulators and policymakers, the paper points to the need for a more innovative governance framework transforming traditional public port entities, focussed on administrative and authoritative functions, into managerial and 
strategically oriented port managing bodies. These PAs should ideally be endowed with forecasting departments capable of supporting port planning and development.

While the paper provides valuable insights, some research limitations can be identified and addressed in further studies. First, future papers could analyse more in-depth the influence exerted by various governmental tiers (e.g. municipality, central government etc.) to PAs in the definition of the methodologies applied to forecasting, as well as in the practical estimation/calculation of the future port throughput. In a similar vein, it would be interesting to scrutinise the diverse approaches of PAs versus other administrative bodies in the definition of the "object" of the forecasting exercise (throughput, vessel size/call size, labour workload, intermodal traffic etc.) as well as the timeframe to be considered (short versus medium versus long term). Third, future research might focus on the quality of the forecasting output produced by PAs, by comparing over time forecasts with actual data, thus measuring gaps. Indeed, inaccuracies and mistakes in forecasting might be discussed and analysed more in depth, also emphasizing the relative impact of this on investment decisions and PA long-term strategies. Fourth, future research can add additional insights by undertaking cross-regional comparisons, through the inclusion of PAs located in other continents. Five, further studies could assess the potential technical conflicts, which may originate from different approaches towards port forecasting by private concessionaires and public actors, and scrutinise viable solutions to overcome these issues. Finally, future contributions could develop extensive empirical analyses in the field, by administering in-depth questionnaires to managers involved in port planning and development, to assess which statistical methodologies they rely on for performing their forecasts, as well as which data and information are processed for supporting PA investment plans.

Acknowledgements The paper has benefited greatly from the interactions and research activities in the Framework of the EC's FP7 Project "PORTOPIA: Ports Observatory for Performance Indicator Analysis". All authors were actively involved in this project.

\section{References}

Bower, J.L. 1983. Managing for efficiency, managing for equity. Harvard Business Review 64: 83-90.

Chan, H.K., S. Xu, and X. Qi. 2018. A comparison of time series methods for forecasting container throughput. International Journal of Logistics Research and Applications. https://doi. org/10.1080/13675567.2018.1525342.

Chen, S.H., and J.N. Chen. 2010. Forecasting container throughputs at ports using genetic programming. Expert Systems with Applications 37 (3): 2054-2058.

Chou, C.C., C.W. Chu, and G.S. Liang. 2008. A modified regression model for forecasting the volumes of Taiwan's import containers. Mathematical and Computer Modelling 47 (9): 797-807.

Coeck, C., T. Notteboom, A. Verbeke, and W. Winkelmans. 1996. A resource-based perspective on strategic port planning. In Proceedings of the 11th international harbour congress, Antwerp, 29-40.

Coto-Millán, P., J. Baños-Pino, and J.V. Castro. 2005. Determinants of the demand for maritime imports and exports. Transportation Research Part E: Logistics and Transportation Review 41 (4): 357-372.

Crossan, M.M., and M. Apaydin. 2010. A multi-dimensional framework of organizational innovation: A systematic review of the literature. Journal of Management Studies 47 (6): 1154-1191. 
Cruz, C.O., and R.C. Marques. 2012. Risk-sharing in seaport terminal concessions. Transport Reviews 32 (4): 455-471.

de Langen, P.W., J. Van Meijeren, and L.A. Tavasszy. 2012. Combining models and commodity chain research for making long-term projections of port throughput: An application to the Hamburg-Le Havre range. European Journal of Transport and Infrastructure Research 12 (3): 310-331.

Duan, X., G. Xu, and S. Yu. 2012. Application of attribute theory for container throughput forecast. In Granular computing (GrC), 2012 IEEE international conference, 102-107.

Farhan, J., and G.P. Ong. 2018. Forecasting seasonal container throughput at international ports using SARIMA models. Maritime Economics and Logistics 20 (1): 131-148.

Flinders, M. 2005. The politics of public-private partnerships. The British Journal of Politics and International Relations 7 (2): 215-239.

Gao, Y., M. Luo, and G. Zou. 2016. Forecasting with model selection or model averaging: A case study for monthly container port throughput. Transportmetrica A: Transport Science 12 (4): 366-384.

Gosasang, V., W. Chandraprakaikul, and S. Kiattisin. 2011. A comparison of traditional and neural networks forecasting techniques for container throughput at Bangkok Port. The Asian Journal of Shipping and Logistics 27 (3): 463-482.

Haimes, Y.Y., and P. Jiang. 2001. Leontief-based model of risk in complex interconnected infrastructures. Journal of Infrastructure Systems 7 (1): 1-12.

Hammami, M., J.-F. Ruhashyankiko, and E.B. Yehoue. 2006. Determinants of public-private partnerships in infrastructure. IMF Working Paper 99: 1-37.

Jacobs, W., and T. Notteboom. 2011. An evolutionary perspective on regional port systems: The role of windows of opportunity in shaping seaport competition. Environment and Planning A 43 (7): 1674-1692.

Jiang, F., and K. Lei. 2009. Grey prediction of port cargo throughput based on GM(1, 1, a) model. Logistics Technology 9: 68-70.

Koppenjan, J.J. 2005. The formation of public-private partnerships: Lessons from nine transport infrastructure projects in The Netherlands. Public Administration 83 (1): 135-157.

Kulkarni, N., and A. Prusty. 2007. Bidding strategy for BOT port terminal projects in India. Journal of Structured Finance 12 (4): 90.

Lam, W.H., P.L. Ng, W. Seabrooke, and E.C. Hui. 2004. Forecasts and reliability analysis of port cargo throughput in Hong Kong. Journal of Urban Planning and Development 130 (3): 133-144.

Lättilä, L., and O.-P. Hilmola. 2012. Forecasting long-term demand of largest Finnish sea ports. International Journal of Applied Management Science 4 (1): 52-79.

McCarthy, T.M., D.F. Davis, S.L. Golicic, and J.T. Mentzer. 2006. The evolution of sales forecasting management: A 20-year longitudinal study of forecasting practices. Journal of Forecasting 25: 303-324.

Metcalfe, L., and S. Richards. 1990. Improving public management, 2nd ed. London: Sage.

Mu, R., M. de Jong, and J. Koppenjan. 2011. The rise and fall of public-private partnerships in China: A path-dependent approach. Journal of Transport Geography 19 (4): 794-806.

Notteboom, T., and J.P. Rodrigue. 2009. The future of containerization: Perspectives from maritime and inland freight distribution. GeoJournal 74 (1): 7-22.

Notteboom, T., F. Parola, G. Satta, and L. Penco. 2015. Disclosure as a tool in stakeholder relations management: A longitudinal study on the Port of Rotterdam. International Journal of Logistics Research and Applications 18 (3): 228-250.

Notteboom, T., and W. Winkelmans. 2001. Reassessing public sector involvement in European seaports. International Journal of Maritime Economics 3 (2): 242-259.

Notteboom, T.E., F. Parola, and G. Satta. 2019. The relationship between transhipment incidence and throughput volatility in North European and Mediterranean container ports. Journal of Transport Geography 74: 371-381.

Notteboom, T.E., and H.E. Haralambides. 2020. Port management and governance in a post-COVID-19 era: Quo vadis? Maritime Economics and Logistics 22 (3): 329-352.

Paixao, A.C., and P.B. Marlow. 2003. Fourth generation ports-A question of agility? International Journal of Physical Distribution and Logistics Management 33 (4): 355-376.

Pallis, A.A., T. Notteboom, and P.W. de Langen. 2010. Concession agreements and market entry in the container terminal industry. Maritime Economics and Logistics 10 (3): 209-228.

Panayides, P.M., F. Parola, and J.S.L. Lam. 2015. The effect of institutional factors on public-private partnership success in ports. Transportation Research Part A: Policy and Practice 71: 110-127.

Pang, G., and B. Gebka. 2017. Forecasting container throughput using aggregate or terminal-specific data? The case of Tanjung Priok Port, Indonesia. International Journal of Production Research 55 (9): 2454-2469. 
Parola, F., and A. Sciomachen. 2009. Modal split evaluation of a maritime container terminal. Maritime Economics and Logistics 11 (1): 77-97.

Parola, F., and S. Maugeri. 2013. Origin and taxonomy of conflicts in seaports: Towards a research agenda. Research in Transportation Business and Management 8: 114-122.

Parola, F., G. Satta, L. Penco, and G. Profumo. 2013a. Emerging Port Authority communication strategies: Assessing the determinants of disclosure in the annual report. Research in Transportation Business and Management 8: 134-147.

Parola, F., T. Notteboom, G. Satta, and J.P. Rodrigue. 2013b. Analysis of factors underlying foreign entry strategies of terminal operators in container ports. Journal of Transport Geography 33: 72-84.

Peng, W.Y., and C.W. Chu. 2009. A comparison of univariate methods for forecasting container throughput volumes. Mathematical and Computer Modelling 50 (7): 1045-1057.

Qiuhong, Z. 2009. Application of Grey model in forecasting the Port of Qinhuangdao's throughput. In 2009 IITA international conference on services science, management and engineering, 57-60.

Rashed, Y., H. Meersman, C. Sys, E. Van de Voorde, and T. Vanelslander. 2015. Scenario-based forecasting of container throughput: A conceptual framework. In International Association of Maritime Economists (IAME) conference 2015, Kuala Lumpur (Malaysia), 24-26 August.

Rashed, Y., H. Meersman, C. Sys, E. Van de Voorde, and T. Vanelslander. 2018. A combined approach to forecast container throughput demand: Scenarios for the Hamburg-Le Havre Range of ports. Transportation Research Part A: Policy and Practice 117: 127-141.

Rashed, Y., H. Meersman, E. Van de Voorde, and T. Vanelslander. 2013. A univariate analysis: Short-term forecasts of container throughput in the Port of Antwerp (No. 2013022).

Rashed, Y., H. Meersman, E. Van de Voorde, and T. Vanelslander. 2017. Short-term forecast of container throughout: An ARIMA-intervention model for the Port of Antwerp. Maritime Economics and Logistics 19 (4): 749-764.

Ripley, B.D. 1994. Neural networks and related methods for classification. Journal of the Royal Statistical Society: Series B (Methodological) 56 (3): 409-456.

Satta, G. 2017. Initial public offerings in the port industry: Exploring the determinants of underpricing. Maritime Policy and Management 44 (8): 1012-1033.

Satta, G., and L. Persico. 2015. Entry mode choices of rapidly internationalizing terminal operators: The determinants of the degree of control on foreign ventures. Maritime Economics and Logistics 17 (1): 97-126.

Satta, G., T. Notteboom, F. Parola, and L. Persico. 2017. Determinants of the long-term performance of initial public offerings (IPOs) in the port industry. Transportation Research Part A: Policy and Practice 103: $135-153$.

Stopford, M. 2009. Maritime economics, 3rd ed. London: Routledge.

Talluri, K. T., and G. J. Van Ryzin. 2004. Estimation and forecasting. In The theory and practice of revenue management, 407-514. New York: Springer.

Taneja, P., W.E. Walker, H. Ligteringen, M. Van Schuylenburg, and R. Van Der Plas. 2010. Implications of an uncertain future for port planning. Maritime Policy and Management 37 (3): 221-245.

Tian, X., L. Liu, K.K. Lai, and S. Wang. 2013. Analysis and forecasting of port logistics using TEI@ I methodology. Transportation Planning and Technology 36 (8): 685-702.

Tranfield, D., D. Denyer, and P. Smart. 2003. Toward a methodology for developing evidence informed management knowledge by means of systematic review. British Journal of Management 14: 207-222.

Trujillo, L., E. Quinet, and A. Estache. 2002. Dealing with demand forecasting games in transport privatization. Transport Policy 9 (4): 325-334.

Twrdy, E., and M. Batista. 2016. Modeling of container throughput in Northern Adriatic ports over the period 1990-2013. Journal of Transport Geography 52: 131-142.

Van Dorsser, J.C.M., M. Wolters, and G.P. Van Wee. 2012. A very long term forecast of the port throughput in the Le Havre-Hamburg Range up to 2100. European Journal of Transport and Infrastructure Research 12 (1): 88-110.

Verhoeven, P. 2010. A review of port authority functions: towards a renaissance? Maritime Policy and Management 37 (3): 247-270.

Vonck, I., and T. Notteboom. 2016. Panarchy within a port setting. Journal of Transport Geography 51: 308-315.

Xiao, Y., J. Xiao, and S. Wang. 2012. A hybrid forecasting model for non-stationary time series: An application to container throughput prediction. International Journal of Knowledge and Systems Science 3 (2): $67-82$. 
Xie, G., S. Wang, Y. Zhao, and K.K. Lai. 2013. Hybrid approaches based on LSSVR model for container throughput forecasting: A comparative study. Applied Soft Computing 13 (5): 2232-2241.

Xu, Z.G. 2011. Based on the prediction of self-regression model of the Port of Shanghai port cargo throughput. Journal of Wuhan Technical College of Communications 13 (1): 71-74.

Zhang, C., L. Huang, and Z. Zhao. 2013. Research on combination forecast of port cargo throughput based on time series and causality analysis. Journal of Industrial Engineering and Management 6 (1): 124.

Publisher's Note Springer Nature remains neutral with regard to jurisdictional claims in published maps and institutional affiliations. 